FACULDADE DE ECONOMIA, ADMINISTRAÇÃO, CONTABILIDADE E CIÊNCIA DA INFORMAÇÃO E DOCUMENTAÇÃO - FACE

ALUÍSIO XAVIER DE MAGALHÃES BRASIL

\title{
AVALIAÇÃO DA QUALIDADE DOS SERVIÇOS PRESTADOS PELA SECRETARIA DE RECURSOS HUMANOS DA UNIVERSIDADE DE BRASÍLIA
}




\section{ALUÍSIO XAVIER DE MAGALHÃES BRASIL}

\section{AVALIAÇÃO DA QUALIDADE DOS SERVIÇOS PRESTADOS PELA SECRETARIA DE RECURSOS HUMANOS DA UNIVERSIDADE DE BRASÍLIA}

Monografia apresentada ao curso de Gestão Universitária do Programa de Pós-Graduação em Administração da Faculdade de Economia, Administração, Contabilidade e Ciência da Informação e Documentação - FACE, da Universidade de Brasília, como requisito para obtenção do grau de especialista em Gestão Universitária.

Orientadora: Prof ${ }^{a}$ M.Sc. Josivania Silva Farias

Brasília - DF 
ALUÍSIO XAVIER DE MAGALHÃES BRASIL

\section{AVALIAÇÃO DA QUALIDADE DOS SERVIÇOS PRESTADOS PELA SECRETARIA DE RECURSOS HUMANOS DA UNIVERSIDADE DE BRASÍLIA}

Monografia apresentada ao curso de Gestão Universitária do Programa de Pós-Graduação em Administração da Faculdade de Economia, Administração, Contabilidade e Ciência da Informação e Documentação - FACE, da Universidade de Brasília, como requisito para obtenção do grau de especialista em Gestão Universitária.

BANCA EXAMINADORA:

Prof $^{\text {a }}$ M.Sc. Josivania Silva Farias (Orientadora)

$\overline{\text { Prof }{ }^{\text {a }} \text { Dr}^{\text {a }} \text { Catarina Cecília Odelius (Examinadora) }}$

$$
\text { Brasília - DF }
$$


Dedico esta monografia a Deus por nunca nos abandonar e nos fortalecer nos momentos mais difíceis, à minha esposa Cinthya, às minhas filhas Ana Beatriz e Maria Fernanda e a todos que torceram pelo sucesso deste trabalho. 


\section{AGRADECIMENTOS}

Agradeço primeiramente a Deus que nunca nos abandona e nos dá força para seguir em frente.

Agradeço à minha esposa, Cinthya, às minhas filhas Ana Beatriz e Maria Fernanda que sempre me apoiaram, participando de todos os momentos e demonstrando enorme compreensão nos momentos mais difíceis.

Agradeço também a Prof ${ }^{a}$ Josivania, pela dedicação demonstrada durante todo o período de orientação, me ajudando com sua enorme capacidade e conhecimento.

Agradeço a todos os meus familiares, em especial à minha Mãe, Maria Ophélia, que mesmo de longe torceu e rezou muito por mim.

Por fim, agradeço a todos que torceram para que eu tivesse sucesso neste trabalho. 
"Nós somos aquilo que fazemos repetidamente. Excelência, então, não é um modo de agir, mas um hábito”.

(Aristóteles) 


\section{Resumo}

A presente pesquisa buscou avaliar a qualidade dos serviços prestados pela Secretaria de Recursos Humanos da Universidade de Brasília a partir do emprego do método SERVQUAL desenvolvido por Parasuraman, Zeitham e Berry (1985) através do qual é possível avaliar a diferença entre a expectativa e percepção dos respondentes, utilizando o modelo de gaps ou lacunas. O resultado destes gaps nos permite conhecer o quão satisfeitos estão os usuários do serviço e não apenas avaliar se os clientes estão satisfeitos ou não. Para isto foram aplicados questionários no período de 16 de março a 09 de abril de 2009 no local de trabalho dos respondentes. De um universo aproximado de 6.000 indivíduos, 125 responderam os questionários, que foram compostos de duas fases, em que a primeira avaliou a expectativa e a segunda a percepção do respondente. Para fundamentar os resultados da pesquisa um expressivo referencial bibliográfico, de diferentes autores, foi estudado, apresentando conceitos sobre serviços, qualidade de serviços, qualidade aplicada ao serviço público, marketing, marketing de serviço e endomarketing. Em seguida, os dados coletados foram tratados com auxílio do software Microsoft Excel 2003. A análise e discussão dos dados permitiram concluir que apesar de os respondentes apresentarem uma boa percepção dos serviços oferecidos, estes ainda estão abaixo de suas expectativas, o que sinaliza para uma avaliação ainda preocupante dos serviços prestados pela Secretaria analisada.

Palavras-chave: qualidade, serviços, marketing, satisfação, SERVQUAL. 


\section{Lista de Figuras}

Figura 1 - Modelo gap de qualidade dos serviços................................................ 18

Figura 2 - Fórmulas para o cálculo dos gaps............................................................ 29

\section{Listra de Gráficos}

Gráfico 1 - Distribuição dos respondentes por sexo................................................. 31

Gráfico 2 - Distribuição por Centro de Custo.......................................................... 33

Gráfico 3 - Resultado dos gaps por item............................................................ 40

Gráfico 4 - Representação dos gaps por dimensão................................................... 42

\section{Lista de Quadros}

Quadro 1 - Classificação das escalas de opinião utilizada no instrumento SERVQUAL 28

\section{Lista de Tabelas}

Tabela 1 - Distribuição dos respondentes por faixa etária

Tabela 2 - Nível de escolaridade dos respondentes ................................................. 32

Tabela 3 - Tipo de vínculo com a Instituição ............................................................. 32

Tabela 4 - Tempo de serviço na Instituição............................................................ 33

Tabela 5 - Médias obtidas na dimensão tangibilidade............................................ 35

Tabela 6 - Médias obtidas na dimensão confiabilidade............................................. 36

Tabela 7 - Médias obtidas na dimensão presteza..................................................... 37

Tabela 8 - Médias obtidas na dimensão segurança.................................................. 38

Tabela 9 - Médias obtidas na dimensão empatia...................................................... 39

Tabela 10 - Representação das médias por dimensão................................................ $\quad 42$ 


\section{SUMÁRIO}

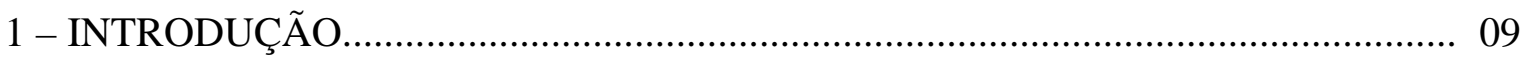

1.1 - O Problema de Pesquisa........................................................................ 10

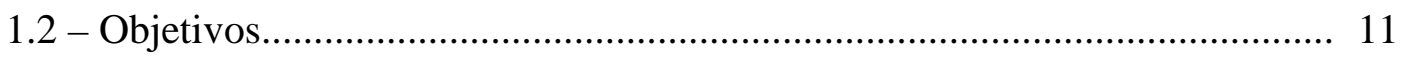

1.2 .1 - Objetivo geral................................................................................. 11

1.2.2 - Objetivos específicos......................................................................... 11

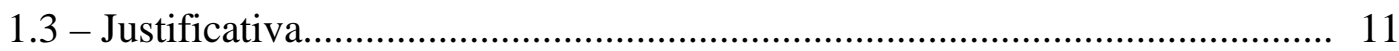

2 - REFERENCIAL TEÓRICO.......................................................................... 13

2.1 - Conceituando serviço............................................................................... 13

2.2 - Qualidade e satisfação........................................................................... $\quad 15$

2.3 - Qualidade no serviço público................................................................... 20

2.4 - Marketing e marketing de serviços.............................................................. 23

3 - METODOLOGIA................................................................................... 26

3.1 - Caracterização da Unidade pesquisada..................................................... 26

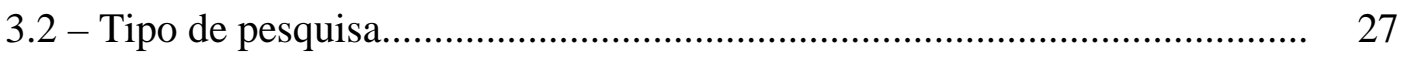

3.3 - Universo e amostra de pesquisa.................................................................. 27

3.4 - Instrumento de coleta de dados............................................................ 28

3.5 - Procedimentos de aplicação dos questionários............................................ 29

3.6 - Procedimentos de análise de dados........................................................... 29

4 - APRESENTAÇÃO E DISCUSS ÃO DOS RESULTADOS..................................... 30

4.1 - Perfil dos respondentes...................................................................... 30

4.2 - Avaliação os gaps da qualidade dos serviços estudados............................. 34

4.2.1 - Aspectos tangíveis............................................................................ 35

4.2.2 - Confiabilidade................................................................................ 36

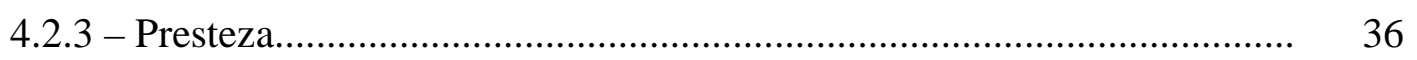

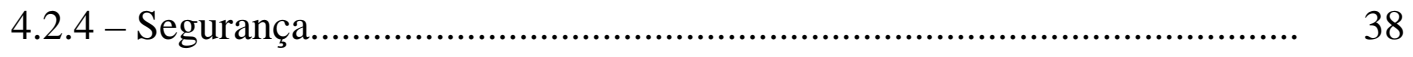

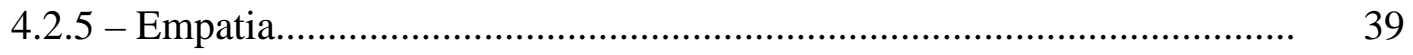

4.3 - Verificação dos gaps por dimensão........................................................... 41

CONSIDERAÇÕES FINAIS...........................................................................

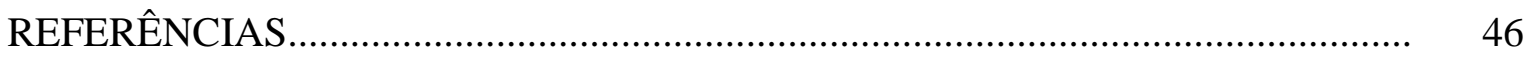

APÊNDICE A: Instrumento utilizado para coleta de dos dados...................................... 49 


\section{1 - INTRODUÇÃO}

A qualidade dos serviços prestados pelas instituições, especialmente as públicas, sempre foi muito questionada pela sociedade de maneira geral. Dependentes deste tipo de atendimento, em diversas áreas, como saúde, educação, segurança, entre outras, enfrentam enormes dificuldades quando necessitam utilizá-los. Conforme relata Ferreira (2000), basta visitar os espaços dedicados aos leitores dos jornais para encontrar uma fonte empírica abundante de reclamações concernentes aos serviços de atendimento em instituições públicas e privadas.

Segundo Ferreira (2000), nota-se o surgimento de um novo usuário-consumidor cada vez mais consciente de seus direitos. Isto vem ocorrendo tanto no setor privado quanto no setor público. Nos últimos anos, com maior facilidade na difusão de informações, a população vem tendo aumentado o seu grau de conhecimento com relação aos seus direitos, tornando-se cada vez mais exigente com relação à eficiência e eficácia dos serviços que lhe são oferecidos. Isto faz com que as instituições se vejam obrigadas a implementar ações que atendam às suas necessidades. Este é um grande desafio a ser atingido. Um aspecto fundamental para que estas instituições atinjam os objetivos é tratar primeiramente da satisfação de seus clientes internos. Será que os servidores, funcionários, colaboradores estão satisfeitos com o tratamento que recebem dentro das organizações em que atuam? Segundo Berry (1996, p.249) "as empresas de serviços excelentes são organizações que alcançam grandes realizações. O esforço para isso é alto. Essas empresas avaliam o desempenho de seus funcionários prestadores de serviços e recompensam sua excelência”.

Pode-se perceber a importância de um quadro funcional trabalhando com satisfação na busca por grandes resultados, e na busca pelos objetivos da instituição. Conhecendo a opinião de seus colaboradores com relação ao que lhes é oferecido, consegue-se mensurar qual o seu grau de satisfação. Ter informações seguras que permitam conhecer a satisfação dos usuários internos é fundamental para estabelecer uma série de medidas e práticas que possibilitem melhorar a qualidade dos serviços ofertados.

Por meio da opinião de seus colaboradores pode-se estabelecer planejamentos estratégicos para combater possíveis falhas e fortalecer ações positivas para melhorar a qualidade dos serviços prestados, e criar ou fortalecer uma boa imagem da Organização perante a sociedade. Trad et al (2001 apud ESPIRIDIÃO; TRAD, 2005) já referenciavam a importância da participação dos usuários nas avaliações dos serviços prestados, pois 
constituem um indicador importante de qualidade, favorecendo uma melhor adequação dos serviços.

Outro aspecto importante a se considerar no âmbito da satisfação dos usuários é a estratégia de marketing a ser adotada. O marketing, conforme Samara (2002), é o conjunto de atividades humanas que tem por finalidade atender os desejos e as necessidades dos clientes por meio de processos de troca, utilizando para isto meios específicos, como a propaganda, a promoção de vendas, a pesquisa de marketing, entre outros. Entretanto, não podemos pensar apenas no marketing externo. O marketing interno também é de extrema importância. Segundo Berry e Parasuraman, (1992, p.180) "satisfazendo as necessidades de seus clientes internos, uma empresa melhora sua capacidade de satisfazer as necessidades dos clientes externos."

Pensando nisto pretende-se estudar qual é a percepção por parte de funcionários da Universidade de Brasília (UnB) com relação à qualidade dos serviços oferecidos pela Secretaria de Recursos Humanos (SRH), qual o grau de satisfação com relação à infraestrutura, ao atendimento prestado pelos servidores, quais as suas expectativas e necessidades, propiciando uma visão real do cenário atual que possa despertar o interesse para sempre buscar alternativas que contemplem, com qualidade, às necessidades do público atendido.

\section{1 - O problema de pesquisa}

Em um mundo globalizado, com constantes inovações tecnológicas, aumento da competitividade entre as empresas, um importante fator a se considerar é o nível de satisfação do cliente. Principalmente no mercado privado, há uma busca incessante para satisfazer ao máximo o cliente e alcançar uma fidelização. E com relação ao serviço público? Será que as pessoas que utilizam estes serviços também precisam estar satisfeitas com o atendimento que lhes é prestado? Respondendo a esta pergunta, podemos começar dizendo que está assegurado na constituição o direito a um serviço público de qualidade. O Art. $6^{\circ}$ da Constituição Federal de 1988 diz : "São direitos sociais a educação, a saúde, o trabalho, a moradia, o lazer, a segurança, a previdência social, a proteção à maternidade e à infância, a assistência aos desamparados, na forma desta Constituição" (BRASIL, 1988).

Porém, antes de se pensar no público externo, a organização deve tratar da satisfação de seus clientes internos, ou seja, seus colaboradores. Se estão satisfeitos, os resultados serão com certeza melhores e consequentemente a satisfação de seus clientes externos será alcançada com mais facilidade: 
Quando as pessoas nas organizações são convidadas a participarem na melhoria dos serviços, a tornarem-se parceiros genuínos em um esforço tão desafiador, sensível e potencialmente gratificante quanto a excelência em serviços, muitas delas fornecerão idéias, energia e espírito à causa (BERRY, 1996, p.19).

Portanto, podemos inferir que, para os objetivos de uma organização serem alcançados, e seus serviços serem prestados de forma eficaz e eficiente, atendendo com qualidade às necessidades dos seus usuários, os colaboradores precisam ser bem tratados pelos diversos segmentos das instituições, estar motivados, satisfeitos e, sobretudo, bem preparados para prestá-los. Com isso, pretende-se responder a seguinte questão: a Secretaria de Recursos Humanos da Universidade de Brasília (SRH/UnB) presta um serviço de qualidade que atenda às expectativas dos seus usuários?

\section{2 - Objetivos}

\subsection{1 - Objetivo Geral}

Identificar o nível da qualidade dos serviços prestados pela SRH/UnB sob a percepção dos usuários.

\subsection{2 - Objetivos Específicos}

- Identificar a expectativa do usuário com relação aos serviços;

- Identificar o grau de satisfação do usuário em relação aos serviços recebidos;

- Conhecer a diferença (gap) entre a expectativa e o desempenho da instituição com relação aos serviços prestados.

\section{3 - Justificativa}

Para que seja ofertado um serviço de qualidade, é necessário conhecer quais as expectativas de seus usuários, e qual o grau de satisfação com relação ao que lhe foi oferecido. A fim de se ter esta percepção, é de suma importância ouvir os próprios usuários. A importância de se estudar este assunto, é tal que Peterson e Wilson (1992 apud CUNHA; BORGES; FACHEL, 1998) relatam que a satisfação e insatisfação têm sido temas frequentes em pelo menos 15.000 artigos práticos e acadêmicos. 
Os serviços públicos são geralmente vistos como um setor que presta um mau atendimento a seus clientes. Porém, antes de visualizar a atuação perante os clientes externos, seria importante uma avaliação de como se sentem os clientes internos das instituições, ou seja, seus funcionários, quais suas necessidades e se estão satisfeitos ou não com a qualidade dos serviços de que necessitam e que lhes são oferecidos internamente. Com isso, estratégias podem ser desenvolvidas, metas estabelecidas, para termos uma melhoria contínua dos serviços, melhorando a sua qualidade, tornando-os mais eficientes e eficazes, consequentemente satisfazendo os clientes externos. Quando se conhece a realidade atual é possível, muitas vezes, adotar medidas simples e de baixo custo que produzam efeitos positivos para os usuários, evitando gastos desnecessários ou investimentos realizados de forma equivocada.

Como se vê, conhecer a satisfação dos usuários é fundamental para estabelecer uma série de medidas e práticas que possibilitem melhorar a qualidade dos serviços ofertados, pois, cada vez mais exige-se um atendimento adequado às suas necessidades.

A SRH/UnB, por ser uma secretaria que, em algum momento, já foi procurada por cada um dos servidores, e que necessita manter contatos frequentes com eles, configura-se em um importante fornecedor de serviços internos, o que a torna um lócus interessante para este estudo.

Outro ponto importante é a nova forma de avaliação dos servidores instituída através da Resolução do Conselho de Administração N. 9/2008 da Fundação Universidade de Brasília (FUB), que é o Programa de Gestão e Avaliação do Desempenho (PROGED) dos integrantes da Carreira dos Cargos Técnico-Administrativos em Educação da FUB, estabelecendo critérios como a avaliação realizada pelos usuários dos serviços. Este novo critério de avaliação impactará diretamente nos aumentos salariais previstos no Plano de Carreira dos servidores técnico-administrativos.

O estudo é viável no que se refere ao tempo, além de ser um campo acessível para o pesquisador, ser amparada por uma consistente bibliografia, e não depender de financiamentos de agências de fomento. 


\section{2 - REFERENCIAL TEÓRICO}

O atendimento ao público é um serviço complexo: sua simplicidade é apenas aparente. Trata-se de uma atividade social mediadora que coloca em cena a interação de diferentes sujeitos em um contexto específico, visando responder a distintas necessidades (FERREIRA, 2000). Vários aspectos, de uma forma ou de outra, influenciam na prestação de serviços, especialmente públicos, relacionando-se diretamente com o nível de satisfação dos usuários que buscam e esperam cada vez mais um atendimento de qualidade, e que tenham suas necessidades plenamente atendidas. Discutiremos estes aspectos com base em diversos autores que discorrem a respeito do assunto.

\section{1 - Conceituando Serviço}

Inicialmente será comentado a respeito de serviços. Cotidianamente se faz uso de algum tipo de serviço, por exemplo, quando utilizamos o telefone, um transporte coletivo, assistimos à televisão, etc. Também percebe-se um alto grau de insatisfação por parte dos usuários, que questionam a todo o momento a qualidade dos serviços oferecidos. No mundo competitivo em que se vive, a prestação de um serviço excelente pode ser o diferencial para garantir a satisfação de seus clientes. Isto pode ser aplicado também aos clientes internos da própria instituição em que se trabalha. Existe certa dificuldade em definir o conceito de serviço. Lovelock e Wright (2003, p.5) apresentam duas definições que capturam a essência dos serviços:

\footnotetext{
- Serviço é um ato ou desempenho oferecido por uma parte à outra. Embora o processo possa estar ligado a um produto físico, o desempenho é essencialmente intangível e normalmente não resulta em propriedade de nenhum dos fatores de produção

- Serviços são atividades econômicas que criam valor e fornecem benefícios para clientes em tempos e lugares específicos, como decorrência da realização de uma mudança desejada no - ou em nome do - destinatário do serviço.
}

Lovelock e Wright (2003, p5) ainda caracterizam os serviços da seguinte forma:

- Intangibilidade: os serviços não podem ser vistos, sentidos, ouvidos, cheirados ou provados antes de adquiridos;

- Inseparabilidade: os serviços são produzidos e consumidos simultaneamente;

- Variabilidade: os serviços são altamente variáveis, pois dependem de por quem, onde e quando são fornecidos; 
- Perecibilidade: os serviços não podem ser estocados.

Já para Gianesi e Corrêa (1994), existem três características essenciais para os serviços:

- São intangíveis, pois, são mais bem definidos como experiências vivenciadas pelos clientes;

- Devem ser produzidos na presença do cliente ou de um bem de sua propriedade;

- A produção e o consumo ocorrem de forma simultânea.

Os autores abordados caracterizam os serviços de maneira bem semelhante, sendo comuns entre eles as características de intangibilidade e da simultaneidade ou inseparabilidade. Os outros itens, pode-se concluir, completam-se e compõem uma ampla descrição do que é considerado serviço.

Apesar de não estar efetivamente brigando por maiores fatias do mercado, ou seja tentando garantir o maior número possível de clientes e assim aumentar seus lucros, as instituições públicas também sentem atualmente a necessidade de prestar um serviço de qualidade. Segundo Meirelles (1994), serviço público é todo aquele prestado pela Administração ou por seus delegados, sob normas e controle estatais, para satisfazer necessidades essenciais ou secundárias da coletividade ou simples conveniências do Estado.

Um primeiro aspecto a ser considerado é a condição de trabalho do servidor para que este preste um bom serviço. Falzon e Lapeyrière (1998 apud FERREIRA, 2000) já discorriam a hipótese de que melhorando as condições de trabalho dos funcionários, tem-se um aprimoramento dos serviços levando à satisfação do usuário. Esta visão também é compartilhada por Albrecht (1994a, 1994b), que diz que não se pode ter clientes externos satisfeitos se os clientes internos não tiverem atendidas suas necessidades e expectativas. Portanto, para que se consiga prestar um bom serviço, satisfazendo as necessidades do usuário, é necessário que o contexto seja avaliado de forma global, abrangendo tanto os clientes internos como os externos. Neste contexto, um segmento fundamental para tornar possível a melhoria nas prestações destes serviços é a gestão de pessoas. O papel dos funcionários é fundamental, pois eles são a própria imagem da organização, portanto as suas necessidades também precisam ser avaliadas e atendidas. A qualificação e a satisfação dos clientes internos influenciarão diretamente nos resultados das instituições. Segundo Malik 
(1998), a Gestão de Pessoas é uma área de difícil atuação e pouco objetiva por tratar com e de pessoas, além do fato de que toda e qualquer pessoa que pertença a uma organização trabalha com ela. Daí a importância e a dificuldade do trabalho desenvolvido e prestado pela SRH.

Las Casas (1997) classifica os serviços como sendo atos, ações e o desempenho. A forma como estes atributos serão aplicados determinará se o serviço é ou não de qualidade. A satisfação do usuário com um determinado serviço está relacionada de maneira direta com o nível da qualidade do serviço que lhe é oferecido.

\section{2 - Qualidade e satisfação}

A origem da palavra qualidade (PINTO, 1993, p.133 apud NASCIMENTO; TROMPIERI FILHO; BARROS, 2005, p.237), é "do latim qualitate e significa a propriedade, atributo, ou condição das coisas ou das pessoas, capaz de distingui-las das outras e lhes determinar a natureza; permitir avaliar e consequentemente aprovar, aceitar ou recusar qualquer coisa”. Conforme Las Casas (1997, p.160), “a qualidade em serviços é a capacidade que uma experiência ou qualquer outro fator tenha para satisfazer uma necessidade, resolver um problema ou fornecer benefícios a alguém”. Portanto, a caracterização de um serviço como sendo um serviço de qualidade pode variar de acordo com as necessidades e expectativas de cada cliente.

Para Kotler (1996, p.5), “satisfação é função da diferença entre o desempenho percebido e as expectativas: se o desempenho ficar abaixo das expectativas, o consumidor ficará insatisfeito, se atender, ficará satisfeito, se exceder, ficará altamente satisfeito, gratificado ou encantado".

Lovelock e Wright (2003, p.103) relatam que as definições baseadas nos serviços igualam qualidade à satisfação do cliente, conforme define a fórmula:

$$
\text { Satisfação = Serviço percebido / Serviço esperado }
$$

Ressaltam, ainda, que a qualidade do serviço é o grau em que um serviço atende ou supera as expectativas do cliente. Ou seja, um serviço pode ser avaliado como de alto nível de qualidade por um determinado cliente e de baixa qualidade por outro, dependendo se tiveram ou não suas necessidades e expectativas atendidas. Com isso, visualiza-se a necessidade e a importância de uma instituição conhecer a percepção do cliente, sabendo, diretamente deste, o que pensa. Somente assim, poderá implementar ações e estratégias que consigam atingir o 
maior número possível de usuários satisfeitos, e, consequentemente, melhorar sua imagem perante a coletividade de funcionários da instituição.

Desta forma, a melhor maneira de medir a qualidade de um determinado serviço é saber do próprio usuário quais as suas expectativas, seus desejos, e o que realmente ele encontrou. Neste sentido, segundo Esperidião e Trad (2005), alguns autores como Parasuraman (1988), e Vaitsman, (2003), dizem que muitas vezes o que se mede não é a satisfação propriamente dita, mas a percepção dos serviços e a expectativa dos usuários. Zeithaml, Berry e Parasuraman (1985 apud MIGUEL; SALOMI, 2004) propuseram a medição de qualidade do serviço, baseados no modelo de satisfação de Oliver (1980), afirmando que a satisfação do cliente é uma função da diferença entre expectativas e desempenho. Esta diferença, denominada gap, segundo Miguel e Salomi (2004), além de ser uma medida da satisfação do cliente, também seria uma medida da qualidade do serviço em relação a uma dimensão específica. O modelo de gaps tem a finalidade de avaliar as falhas na qualidade dos serviços (Figura 1). Este modelo foi apresentado resumidamente por Amaral, Pinto e Miranda (2002) da seguinte forma:

- Gap 1 - Expectativa dos clientes - percepção da gerência: pode haver discrepâncias entre a percepção da gerência com relação às expectativas dos clientes

- Gap 2 - Especificação da qualidade do serviço: as especificações da qualidade dos serviços não correspondem às expectativas dos clientes;

- Gap 3 - Execução do serviço: os padrões de atendimento fornecido através das pessoas que mantêm o contato direto com o cliente não condizem com os padrões de qualidade especificados pela empresa, provocando a percepção de um serviço de qualidade inferior;

- Gap 4 - Comunicação externa: discrepância entre o que é divulgado através dos serviços de comunicação e marketing da empresa e o que realmente é oferecido;

- Gap 5 - Serviço esperado - Serviço percebido: discrepância entre o serviço esperado, ou seja, a expectativa do cliente e o que é percebido, estando diretamente dependentes dos outros gaps.

Autores como Hoffman e Bateson (2006, p. 359 apud MUNDIM; AUGUST, 2008) denominam estes gaps como lacuna de serviço, que seria a distância entre a expectativa do cliente e sua percepção relacionada ao serviço que realmente é prestado. 
Hoffman e Bateson (2006 apud MUNDIM; AUGUST, 2008) referem-se às lacunas da seguinte maneira:

a) lacuna de conhecimento: refere-se à diferença entre o que o cliente espera e a percepção da gerência com relação ao que ele espera.

b) lacuna de padrões: exprime a diferença entre o que a gerência percebe que os clientes esperam e as especificações de qualidade estabelecidas para a prestação do serviço;

c) lacuna da execução: refere-se à diferença entre as especificações de qualidade que foram estabelecidas para o serviço que é prestado e a qualidade realmente encontrada;

d) lacuna de comunicações: é diferença entre a qualidade que o serviço prestado realmente possui e a qualidade que a empresa divulga por meio de suas comunicações externas.

Pode-se perceber que, apesar de denominações diferentes, gap ou lacuna, os autores apresentam o mesmo objetivo, ou seja, apresentar meios que possam identificar da melhor maneira possível a diferença entre as expectativas dos clientes e o que realmente lhes é oferecido pelas organizações prestadoras de serviço. Com isso, é possível fornecer subsídios para que as gerências tomem medidas adequadas no sentido de proporcionar aos clientes a qualidade que eles realmente esperam.

Amaral, Pinto e Miranda (2002) referem-se ao modelo de gaps (Figura 1) como sendo uma importante ferramenta gerencial, que permite a identificação das falhas na qualidade dos serviços. 


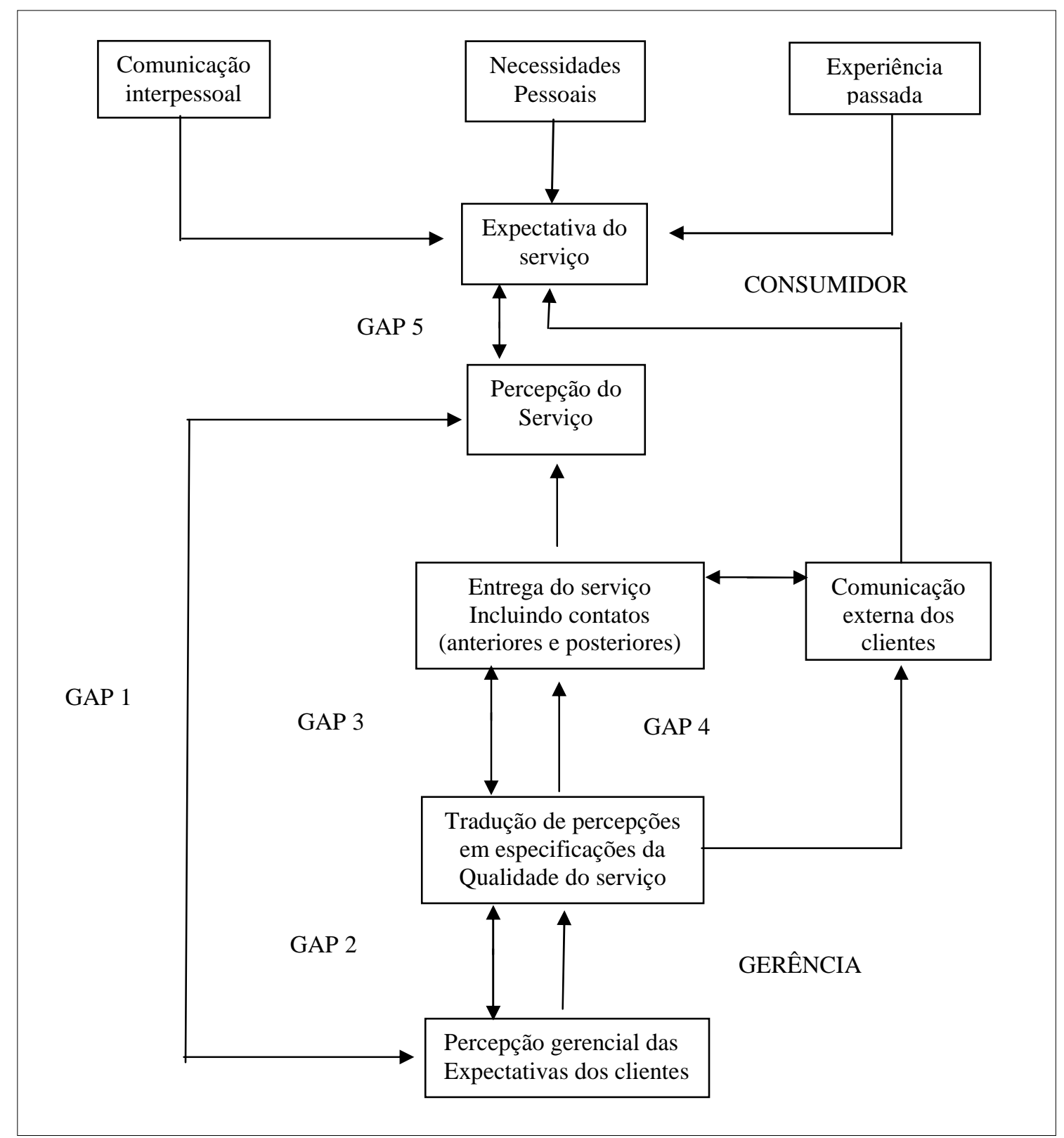

Figura 1: Modelo gap de Qualidade dos Serviços

Fonte: Parasuraman et al. (1985 apud MIGUEL; SALOMI, 2004, p.16).

Neste estudo será considerado o gap 5, que traduzirá a lacuna ou a discrepância existente entre a expectativa do usuário da SRH/UnB e sua percepção do serviço oferecido.

Grönrros (1984 apud MIGUEL; SALOMI, 2004) considera a qualidade percebida de um serviço como função do serviço esperado e do serviço percebido, incluindo um terceiro fator, chamado imagem da empresa.

Domingues e Allipandrine (1998) basearam-se em diversos autores (GHOBADIAN, SPEILER E JONES, 1994; GIANESI E CORRÊA, 1994;BERRY E ZETHML, 1990) para definir um conjunto de determinantes da qualidade utilizados como critérios na avaliação de Serviço: 
- Confiabilidade: habilidade de prestar o serviço de forma confiável, precisa e consistente;

- Responsabilidade: sua importância está na possibilidade ou não do fornecedor resolver as queixas e problemas imediatos do serviço, requisitados pelo cliente;

- Adaptabilidade: habilidade do fornecedor de ajustar o serviço de forma a atender às necessidades dos clientes;

- Tangíveis: refere-se à aparência das instalações físicas, dos equipamentos, dos funcionários e dos materiais de comunicação;

- Comunicação: aqui os clientes avaliam a capacidade do fornecedor de mantê-los informados sobre o serviço numa linguagem que eles entendam, além de ouvir suas sugestões;

- Entender/conhecer o cliente: envolve os esforços no atendimento às necessidades do cliente e requisições específicas, dar atendimento individualizado, e reconhecer o cliente regular;

- Consistência: significa conformidade com experiência anterior, ausência da variabilidade no resultado ou no processo. É importante para clientes que querem saber o que esperar de um serviço. Quando um cliente é atendido por um fornecedor de serviço e a experiência é satisfatória, isto somente o induzirá a repetir a compra do serviço se ele tiver o mínimo de segurança de que o fornecedor pode repetir o feito;

- Competência: refere-se à habilidade e ao conhecimento do fornecedor para executar o serviço, relacionando-se às necessidades "técnicas" dos consumidores. Importante para serviços profissionais, nos quais o cliente procura uma capacitação da qual não dispõe;

- Velocidade de atendimento: refere-se à prontidão da empresa e de seus funcionários em prestar o serviço rapidamente. O tempo que o cliente tem que despender para receber o serviço é, normalmente, considerado um tempo perdido;

- Atendimento/atmosfera: refere-se ao quão agradável é a experiência que o cliente tem durante o processo de prestação de serviço. Atenção personalizada e cortesia dos funcionários são fundamentais para criar uma boa percepção;

- Flexibilidade: refere-se à habilidade de reagir eficaz e rapidamente a possíveis mudanças inesperadas nas expectativas dos clientes, no processo e suprimento de recursos. É importante devido à alta variabilidade e incerteza presentes no processo de prestação de serviços, principalmente no front Office;

- Credibilidade/segurança: refere-se à formação de uma baixa percepção de risco no cliente e à habilidade de transmitir confiança física, financeira e confidencial;

- Acesso: facilidade que o cliente tem em entrar em contato com o fornecedor de serviço como: localização conveniente, acesso sinalizado, disponibilidade de estacionamento, amplo horário de operação, ampla disponibilidade de linhas telefônicas, etc.;

- Custo: critério que avalia o quanto o consumidor irá pagar por determinado serviço.

Percebe-se que diferentes autores apresentam conceitos bem parecidos com relação à definição da qualidade de um serviço, estando sempre relacionados à percepção por parte do usuário. Zeithaml, Berry e Parasuraman (1985 apud MIGUEL; SALOMI, 2004) desenvolveram o modelo SERVQUAL, capaz de medir a diferença entre o serviço esperado e o desempenho, que se traduzirá na qualidade dos serviços. Este instrumento é composto de vários itens que permitem avaliar as cinco dimensões da qualidade de serviço:

- Aspectos tangíveis: compreendem os aspectos físicos, como instalações, equipamentos, funcionários envolvidos no atendimento, material utilizado; 
- Confiabilidade: capacidade de realizar os serviços de forma confiável, dentro de um prazo determinado com informações precisas e consistentes. Estes fatores terão um impacto significativo na qualidade dos serviços;

- $\quad$ Presteza: representa a capacidade de atender prontamente o indivíduo, facilitando o seu acesso aos serviços oferecidos;

- Segurança: capacidade de transmitir segurança na transmissão das informações. A segurança pode ser refletida no esforço do funcionário para prestar um atendimento que inspire confiança;

- Empatia: atitude de fornecer um atendimento individualizado com interesse em satisfazer às necessidades do cliente com cortesia.

Dentre estas cinco dimensões, Berry e Parasuraman (1992) afirmam que, de acordo com estudos, a confiabilidade é a mais importante conforme a opinião dos clientes. Segundo Berry (1996, p.80) “independente do setor de serviços que estudamos, os clientes sempre consideravam a confiabilidade como a característica mais importante na avaliação da qualidade de um serviço".

Zeithaml, Berry e Parasuraman (1985 apud MIGUEL; SALOMI, 2004) afirmam que os clientes avaliam a qualidade dos serviços de forma global, de modo similar a uma atitude. Neste sentido, para Bateson (2001 apud NOGUEIRA, 2004) "a qualidade de serviço é uma atitude formada por uma avaliação global de longo prazo de um desempenho". Infere-se, portanto, que a proposta de dividir os aspectos da qualidade por dimensões é um auxílio para avaliação da qualidade dos serviços que vai facilitar a análise gerencial e permitir a atuação em pontos específicos. No entanto, do ponto de vista do cliente esta separação geralmente não é visualizada, bastando um item estar abaixo da expectativa para que possa gerar no cliente uma sensação de insatisfação e consequentemente formar uma opinião negativa a respeito da empresa ou organização.

\section{3 - Qualidade no serviço público}

Segundo Berry (1996, p.79),

uma vez que serviços de qualidade são parte integrante da criação de valor para o cliente, eles devem sempre constituir o foco da estratégia de serviços. Serviços de qualidade estão na base da criação de valor; são o alicerce necessário para a 
construção de tudo o mais que a estratégia de serviços possa conter. Por outro lado, os serviços de qualidade apóiam-se em confiabilidade, surpresas, recuperação e integridade - os princípios da criação de uma excelência em serviços. Sem esses princípios é impossível manter a confiança dos clientes.

Para os gestores das instituições públicas prestadoras de serviços, da mesma forma que nas instituições privadas, cada vez mais se torna fundamental o conhecimento da visão do usuário (cliente) para o estabelecimento de metas e estratégias administrativas, inclusive otimizando a aplicação de recursos, de forma a possibilitar investimentos nas áreas que realmente necessitam.

Buscando a melhoria da qualidade dos serviços públicos e a promoção do aumento de competitividade no País, o governo federal instituiu através do Decreto $n^{\circ} 5.378$ de 23 de fevereiro de 2005 o Programa Nacional de Gestão Pública e Desburocratização - GesPública. Resultado da fusão dos Programas de Qualidade no Serviço Público (PQSP) e Nacional de Desburocratização (PND), o GesPública é uma arrojada política pública, com foco na promoção e expansão da cidadania e fortalecimento da democracia, além de privilegiar uma gestão pública ética, transparente, participativa, descentralizada, com controle social e orientada para o cidadão. Está baseada em três características:

- É essencialmente pública, ou seja, a gestão de órgãos e entidades públicos apresenta condições de buscar a excelência, comparadas a padrões internacionais de qualidade em gestão, porém, não pode e nem deve deixar de ser pública;

- É Focada em resultados, isto é, produzir mais e melhores resultados para o cidadão, com impacto na melhoria da qualidade de vida, atendendo com eficiência e eficácia as demandas da sociedade traduzidas pelos governos em políticas públicas;

- É Federativa, ou seja, aplica-se a toda a administração pública, não estando limitado a um objetivo específico a ser gerenciado (saúde, educação, previdência, saneamento, tributação, fiscalização, etc.).

Percebe-se que a busca pela qualidade do serviço público tem sido uma tendência nos últimos anos, haja vista este programa de tamanha proporção instituído pelo Governo Federal e conduzido pelo Ministério do Planejamento, Orçamento e Gestão. Como o próprio nome do programa refere, um dos aspectos que mais atravancam o desenvolvimento do serviço público é a burocracia excessiva. Muitas vezes ela impede que o serviço seja prestado de forma eficaz 
e eficiente e chegue com qualidade a realmente quem necessita, ou seja, um serviço voltado para o cidadão. Isto passa necessariamente pela modernização do serviço público. Segundo Ramos (2004), “a modernização do serviço público é uma necessidade econômica decorrente das pressões da concorrência internacional, que impõe, ao mesmo tempo, uma necessidade de transparência e de revalorização do papel do próprio serviço junto aos usuários e aos cidadãos." É preciso que haja no serviço público formas que estimulem a criatividade dos funcionários, que façam com que eles saiam de uma posição extremamente passiva e promovam através do desenvolvimento do seu potencial criativo uma administração mais participativa e cidadã, melhorando a imagem da organização perante a sociedade. Segundo Osborne e Gaebler (1997 apud RAMOS, 2004), a transformação de burocracias públicas em governos empreendedores, produtivos e eficientes esta intimamente relacionada com o ceticismo do cidadão sobre a capacidade do Estado em administrar a sociedade e satisfazer suas crescentes e complexas necessidades sociais.

Para alcançar esta excelência em qualidade, um fator preponderante é a valorização dos recursos humanos. Conforme Vallemont (1996, p. 11 apud MOURA; SOUZA, 2008), “a modernização do Estado passa tanto - ou mais - pelos homens quanto pelas estruturas [e] a valorização dos recursos humanos é o ponto de passagem obrigatório de toda modernização". Caracteriza-se aqui o papel fundamental da SRH nesta modernização. Segundo Malik (1998, p.2) "a Administração de Recursos Humanos serve para manter a organização produtiva, eficiente, eficaz, a partir da mobilização adequada das pessoas que ali trabalham."

Malik (1998, p.2) afirma ainda que “a Administração de Recursos Humanos pode ser compreendida como um subsistema de uma organização. Afinal são as pessoas que realizam o trabalho das organizações."

Segundo Moura e Souza (2008),

a modernização do Estado, portanto, passa necessariamente pela modernização da gestão de pessoal. Há que se valorizar os servidores e prepará-los para o exercício de suas responsabilidades, de forma que compreendam o seu papel e a sua importância na construção de um Estado eficaz e se sintam parte integrante desse processo. Contudo, embora os servidores tenham um papel especialmente importante na construção de um Estado que funcione de forma eficiente e eficaz, é comum encontrar servidores desmotivados, pouco qualificados $\mathrm{e}$ inadequadamente preparados para o desenvolvimento de suas atividades. A ausência de um quadro de servidores qualificados compromete tanto o gerenciamento quanto a formulação de políticas públicas. 
Pelo que foi apresentado, a busca pela qualidade, pela prestação de um serviço excelente será um grande desafio para os funcionários públicos e terá papel fundamental dentro dos planejamentos estratégicos que estarão sendo traçados pelos gestores dos serviços públicos. Para Berry (1996, p. 272) "prestar um excelente serviço é mais divertido para os funcionários do que prestar um serviço medíocre. O serviço excelente é um trabalho árduo, mas trabalho árduo não é o que acaba com um profissional; o trabalho sem desafio, sim, este mata o bom profissional".

\section{4 - Marketing e marketing de serviços}

O marketing se tornou uma ferramenta importante no auxílio ao desenvolvimento das instituições no que diz respeito à prestação de serviços de qualidade, pois, como vimos, o conceito de qualidade dependerá da expectativa do cliente com relação ao serviço de que necessita. Desta forma o marketing trabalhará no sentido de conhecer e explorar as relações do cliente com a instituição.

Segundo Las Casas (1997, p. 26),

marketing é a área do conhecimento que engloba todas as atividades concernentes às relações de troca, orientadas para a satisfação dos desejos e necessidades dos consumidores, visando alcançar determinados objetivos da empresa ou indivíduos e considerando sempre o meio ambiente de atuação e o impacto que essas relações causam no bem-estar da sociedade.

Cobra e Zwarg (1986) dizem que o marketing lida com os problemas porque passa por uma organização que produz bens e serviços que vão satisfazer as necessidades de um grupo determinado de pessoas. Já para Lima e Silva (2007), o marketing consiste no conjunto de atividades que torna possível que a realização de trocas sejam realizadas com vantagens ou não. Kotler (1996), por sua vez, define marketing como sendo um processo de análise, planejamento, implantação e controle de programas destinados a levar a efeito as trocas desejadas com públicos visados e tendo por objetivo o ganho pessoal ou mútuo. Ele se baseia fortemente na adaptação e na coordenação de produto, preço, promoção e lugar para alcançar uma reação eficiente.

Percebe-se que os autores definem marketing de maneira bem parecida, todas elas realçando a relação com as necessidades do cliente, o que leva a se pensar em constantes autoavaliações dos serviços por parte das empresas, no sentido de estarem sempre alcançando e 
superando as expectativas do seu público. Isso torna o marketing um importante instrumento de gestão na busca pela qualidade e excelência dos seus serviços.

Ainda no aspecto de marketing relacionado a serviço, não se pode deixar de ressaltar a importância da dimensão confiabilidade. Segundo Berry e Parasuraman (1992, p. 29), “a confiabilidade do serviço - o desempenho confiável e preciso do serviço - é o coração da excelência do marketing de serviços". Ainda de acordo com estes autores, em cada estudo realizado que se media a importância das cinco dimensões, como já foi exposto anteriormente, a confiabilidade sempre aparece como a mais crucial de acordo com a opinião dos usuários.

No contexto deste trabalho, é imprescindível se destacar também o endomarketing. Segundo Silva (2003), as técnicas de endomarketing buscam alcançar os objetivos da organização através da constatação de que o colaborador pode ser visto como cliente e os cargos como produto, realizando esforços para oferecer um produto interno que satisfaça os desejos e necessidades destes clientes internos

Segundo Las Casas, (1999, p. 114 apud SILVA, 2003),

\footnotetext{
ao analisar o marketing interno ou endomarketing, pode-se pensar em marketing aplicado na atividade de Recursos Humanos. Praticamente, o departamento de RH é que tem comercializado e feito a união entre empresa-funcionário, como também se responsabilizado pelo nível motivacional da equipe. No entanto, pouca atenção era dada às técnicas convencionais de marketing na execução destes trabalhos, sendo atribuído a transações externas apenas.
}

As estratégias de marketing se baseiam em condições que possam gerar nos clientes meios de perceber o tipo de serviço que determinado segmento é capaz de oferecer. Neste aspecto, as informações devem ser transmitidas de maneira clara e acessível ao público que se deseja alcançar. Com isso, a comunicação com os clientes, seja ele interno ou externo é um fator importante, pois, através dela, torna-se possível fornecer as evidências de que o usuário necessita para procurar ou avaliar a qualidade de um determinado serviço. Inclui-se aí a comunicação tanto para atrair clientes como a realizada durante o processo de atendimento. É fundamental que os funcionários saibam atender com qualidade e transmitam confiança aos usuários. "As empresas de serviço que administram com eficácia as comunicações fazem-no enfatizando as evidências existentes e criando novas" (BERRY; PARASURAMAN, 1992, p.119). 
Apesar de o setor de serviços caracterizar-se principalmente pelos aspectos intangíveis, não se pode deixar de referenciar a importância dos aspectos tangíveis. Neste sentido a aparência física é um fator relevante. O local onde se presta o atendimento deve proporcionar condições adequadas para prestação do serviço a que se destina, oferecendo principalmente conforto aos seus usuários, além de causar-lhes uma sensação de bem estar. Da mesma forma, os equipamentos disponíveis e materiais utilizados devem ser adequados ao desenvolvimento do serviço a que se propõe. Segundo Cobra (2001 apud SABINO, 2004), a qualidade dos serviços apresenta-se em duas dimensões: a instrumental, que descreve os aspectos físicos de um serviço e a dimensão funcional, que se refere aos aspectos intangíveis ou psicológicos do desempenho do serviço.

Analisando a opinião destes autores, percebe-se a importância de se avaliar constantemente os processos, para que estes acompanhem o desenvolvimento e mudanças que se presencia rotineiramente em todos os segmentos.

Pelos aspectos apresentados até aqui, verifica-se a importância de realizar um estudo que avalie a qualidade dos serviços prestados pela $\mathrm{SRH} / \mathrm{UnB}$, no sentido de estimular e fornecer subsídios que possibilitem aos gestores adequar medidas que propiciem investimentos mais adequados e ofereçam um serviço de qualidade. 


\section{3 - METODOLOGIA}

O sucesso de uma pesquisa está diretamente relacionado ao modelo metodológico que será utilizado. Para que os objetivos sejam plenamente alcançados deve-se optar por um método que contemple amplamente o problema de pesquisa. Segundo Diehl e Tatim (2004, p. 46), "a pesquisa constitui-se num procedimento racional e sistemático, cujo objetivo é proporcionar respostas aos problemas propostos. Ao seu desenvolvimento é necessário o uso cuidadoso de métodos, processos e técnicas".

Nesta etapa serão descritos a metodologia e os procedimentos técnicos que foram adotados considerando os objetivos propostos.

\section{1 - Caracterização da Unidade pesquisada}

Foi avaliada neste estudo a qualidade dos serviços prestados pela SRH/UnB do ponto de vista dos usuários participantes (respondentes) da pesquisa. Segundo informações disponíveis na internet via http://www.srh.unb.br, acessado em 24 de abril de 2009, a SRH/UnB está vinculada ao Gabinete do Reitor e tem como competência formular e desenvolver a política de recursos humanos da UnB, a partir dos planos de carreira e propostas formuladas pelos fóruns de RH. Além disso, assessora a Reitoria nas decisões relativas ao pessoal vinculado à instituição.

As suas funções são de planejamento, coordenação, controle e supervisão. Possui como atividades o recrutamento, seleção, ingresso, movimentação, avaliação, capacitação, desenvolvimento humano e qualidade de vida, registros funcionais, operações financeiras, aposentadoria e pensão.

Está localizada no Campus Universitário Darcy Ribeiro, Gleba A, Reitoria, Bloco A - $1^{\circ}$ andar. A SRH/UnB possui ainda dois postos de atendimento avançados:

- PA/HUB - Posto avançado localizado no Hospital Universitário de Brasília;

- PA/PRC - Posto avançado localizado na Prefeitura do Campus.

Dentre outras unidades, está vinculada à SRH/HUB a Gerência de Capacitação, que inclui o PROCAP. Este tem por missão a atualização dos Recursos Humanos da UnB, visando à qualidade dos seus serviços, e por princípios a melhoria da qualidade de vida e da qualificação profissional; a adequação do perfil de servidores e colaboradores aos diversos ambientes organizacionais; a valorização da sua participação nos programas desta Universidade e processo contínuo de treinamento como agente motivador de participação. 
Tem, ainda, como objetivo da equipe desenvolver atividades de capacitação, visando ao atendimento das reais demandas do trabalho, às necessidades da UnB e da sociedade

\section{2 - Tipo de pesquisa}

Foi realizada uma pesquisa descritiva, de caráter quantitativo por meio de estudo de caso. Segundo Vergara (2000), várias taxonomias de tipos de pesquisa existem e são utilizados por diversos autores em suas pesquisas.

A pesquisa pode ser classificada pelos fins a que se destinam e pelos meios utilizados na investigação. Este estudo trata-se de uma pesquisa descritiva por "expor características de determinada população ou fenômeno" (VERGARA, 2000, p.47). É quantitativa por utilizar um processo de quantificação na coleta de dados além de utilizar técnicas estatísticas que permitam tratar as informações coletadas (DIEHL; TATIM, 2004).

Trata-se de um estudo de caso, pois é uma análise aprofundada da qualidade dos serviços prestados pela SRH/UnB sob a visão do usuário. Segundo Diehl e Tatim (2004, p. 61), o estudo de caso "caracteriza-se pelo estudo profundo e exaustivo de um ou de poucos objetos, de maneira que permita seu amplo e detalhado conhecimento".

Ainda segundo Diehl e Tatim (2004, p. 61) o estudo de caso como método de pesquisa pode ser definido como "um conjunto de dados que descrevem uma fase ou a totalidade do processo social de uma unidade, em suas diversas relações internas e em suas fixações culturais, quer essa unidade seja uma pessoa, uma família, um profissional, uma instituição social, uma comunidade ou uma nação".

\section{3 - Universo e amostra de pesquisa}

Segundo Diehl e Tatim (2004), para se conhecer as características de uma determinada população, é comum que uma pesquisa científica utilize-se apenas de uma amostra de seus elementos. A partir dos dados levantados são obtidos valores aproximados ou estimados relacionados às características da população de interesse.

A Universidade de Brasília conta hoje com aproximadamente 6.000 funcionários, entre professores, servidores e prestadores de serviços, além de estagiários. Foram distribuídos 200 questionários a indivíduos que tivessem algum destes vínculos com a Instituição, através de amostragem não probabilística por acessibilidade do pesquisador aos 
respondentes. Destes, obtivemos o retorno de 125 questionários respondidos, os quais foram considerados para esta pesquisa.

\section{4 - Instrumento de coleta de dados}

A coleta de dados foi efetuada por meio de questionário não disfarçado, com questões fechadas, em uma perspectiva temporal de coleta baseada na transversalidade, com o objetivo de verificar a diferença entre o serviço esperado e o percebido, que resultou na visão que os respondentes possuem da qualidade dos serviços prestados pela SRH/UnB. Para isso, foi utilizado o modelo de escala SERVQUAL desenvolvido por Parasuraman, Zeitham e Berry (1988 apud CUNHA, 2004). Esta escala, segundo Rodrigues (2001, p.119 apud DETTMER; SOCORRO; KATON, 2002, p.10), "ainda que seja objeto de críticas tanto conceitual quanto metodológico, é considerado por muitos autores no domínio do marketing um instrumento adequado ao estudo da problemática da qualidade de serviços".

A escala SERVQUAL pode ser aplicada em organizações do setor de serviços, tendo sido testada pelos seus autores quanto à fidedignidade e validade. É multidimensional por possibilitar a avaliação de cinco dimensões da qualidade, tais como: tangibilidade, confiabilidade, presteza, segurança e empatia. Estas dimensões foram avaliadas por meio dos 20 itens que compõem o instrumento citado, utilizando escala tipo Likert de 1 a 7 pontos.

As escalas de opinião do tipo Likert que foram utilizadas para mensurar as características dos quesitos expectativas e percepções seguiram os seguintes escores (Quadro 1), conforme os pesos que lhe foram atribuídas:

\begin{tabular}{|l|l|l|}
\hline Pesos & \multicolumn{2}{|c|}{ FASES DA PESQUISA } \\
\hline $\mathbf{N}$ & \multicolumn{1}{|c|}{ Fase 01: Expectativas } & \multicolumn{1}{c|}{ Fase 02: Percepções } \\
\hline $\mathbf{1}$ & Não é importante & Péssimo (não atende às expectativas) \\
\hline $\mathbf{2}$ & Pouco importante & Ruim \\
\hline $\mathbf{3}$ & Relativamente importante & Regular \\
\hline $\mathbf{4}$ & Importante & Bom \\
\hline $\mathbf{5}$ & Bem importante & Muito Bom \\
\hline $\mathbf{6}$ & Muito importante & Ótimo \\
\hline $\mathbf{7}$ & $\begin{array}{l}\text { Extremamente importante } \\
\text { (imprescindível) }\end{array}$ & Excelente (atende plenamente às expectativas) \\
\hline
\end{tabular}

Quadro 1: Classificação das escalas de opinião utilizada no instrumento SERVQUAL. Fonte: Dados da pesquisa de campo, 2009 


\section{5 - Procedimentos de aplicação dos questionários}

Os questionários foram aplicados pessoalmente pelo pesquisador, em formulário impresso, nos locais de trabalho dos respondentes. Em alguns casos, devido à indisponibilidade de tempo no momento, os questionários foram deixados para serem respondidos e recolhidos posteriormente. A aplicação dos questionários ocorreu no período de 16 de março a 09 de abril de 2009.

\section{6 - Procedimentos de análise de dados}

A fim de encontrar respostas aos objetivos propostos nesta pesquisa foi realizada uma análise descritiva dos dados com auxílio do software Microsoft Excel 2003, para calcular as médias ponderadas para verificação dos gaps.

Foi utilizada a seguinte fórmula (Figura 2) para verificação dos gaps através do cálculo de médias ponderadas:

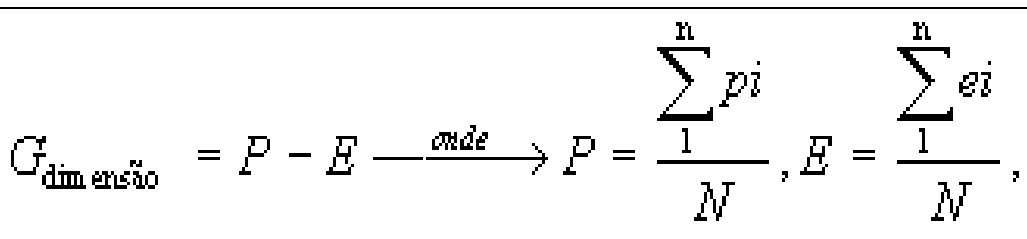

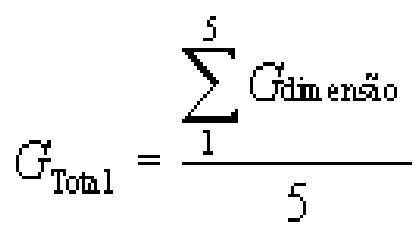

$$
\begin{aligned}
& \mathrm{G}=\text { Expectativa }- \text { Percepção }
\end{aligned}
$$

Figura 2: Fórmulas para o cálculo dos gaps

Fonte: Parasuraman; Berry; Zeithaml (1988 apud PEREIRA; FARIAS, 2005, p.7)

Onde:

$\mathrm{G}=$ gap/hiato

$\mathrm{E}=$ expectativa

$\mathrm{P}=$ percepção

$\mathrm{N}=$ total de observações/entrevistados

$\mathrm{n}=$ total de ocorrências para cada peso da escala 


\section{4 - APRESENTAÇÃO E DISCUSSÃO DOS RESULTADOS}

Serão apresentados neste capítulo os resultados obtidos por meio do tratamento estatístico dos dados coletados, a partir dos quais será possível estabelecer uma relação com os objetivos geral e específicos propostos. Os dados obtidos avaliaram o perfil do respondente, a sua expectativa em relação ao serviço oferecido, a sua percepção com relação ao serviço que recebe atualmente. Com isto foi possível obter os gaps entre o serviço esperado e o serviço recebido.

Utilizando os dados obtidos por meio da Escala SERVQUAL, é possível a obtenção de três tipos de resultados referentes aos gaps:

- Expectativas < Percepções : a qualidade dos serviços supera as expectativas do cliente. Neste caso o gap apresenta valor negativo;

- $\quad$ Expectativas $=$ Percepções: a qualidade satisfaz a expectativa do cliente;

- Expectativas > Percepções: a qualidade percebida está abaixo da expectativa do cliente, podendo gerar insatisfação. Neste caso o gap apresenta valor positivo.

\subsection{Perfil dos respondentes}

Foi realizada uma avaliação do perfil dos funcionários/usuários dos serviços da $\mathrm{SRH} / \mathrm{UnB}$ que participaram voluntariamente da pesquisa. Para isto foram consideradas as seguintes variáveis: gênero, faixa etária, escolaridade, tipo de vínculo empregatício com a instituição, centro de custo e tempo de serviço. Vale ressaltar que esta avaliação não faz parte dos objetivos traçados para este estudo, e as variáveis apresentadas não foram consideradas isoladamente, ou seja, a avaliação das expectativas e percepções foram analisadas de forma agrupada. Porém é de muita importância conhecer o público que se conseguiu atingir com esta pesquisa para avaliações futuras.

$\mathrm{Na}$ variável sexo obtiveram-se 67 respostas de indivíduos do sexo feminino, correspondente a $53,6 \%$ do total e 58 respostas de indivíduos do sexo masculino, correspondente a 46,4\%. Percebe-se um percentual ligeiramente maior de respondentes do sexo feminino conforme demonstrado no Gráfico 1: 


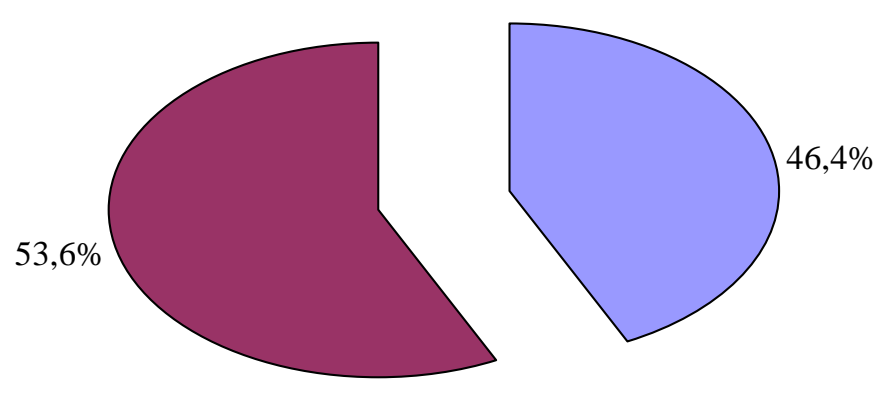

Grafico 1: Distribuição dos respondentes por sexo

Fonte: Dados da pesquisa de campo, 2009

Em relação à idade dos participantes (Tabela 1), 34 ou 27,2\% dos indivíduos estão na faixa de 18 a 29 anos, mesmo percentual da faixa entre 40 e 49 anos; 43 ou 34,4\% estão entre 30 e 39 anos; 12 ou 9,6\% entre 50 e 59 anos;e 2 ou 1,6\% estão acima de 60 anos. Percebe-se um predomínio de funcionários com idade em torno dos 30 anos.

\begin{tabular}{|l|c|c|}
\hline Faixa etária & Freqüência & Percentual(\%) \\
\hline 18 a 29 anos & 34 & 27,2 \\
\hline 30 a 39 anos & 43 & 34,4 \\
\hline 40 a 49 anos & 34 & 27,2 \\
\hline 50 a 59 anos & 12 & 9,6 \\
\hline Acima de 60 anos & 2 & 1,6 \\
\hline Total & 125 & 100 \\
\hline
\end{tabular}

Tabela 1: Distribuição dos respondentes por faixa etária Fonte: Dados da pesquisa de campo, 2009

Outra variável pesquisada foi o grau de escolaridade (Tabela 2). Os dados mostraram que $34,4 \%$ dos respondentes possuem ensino médio completo, $18,4 \%$ estão cursando curso superior, $36,8 \%$ possuem curso superior completo e $6,4 \%$ possuem pós graduação com título de especialista. Mostraram ainda que 1,6\% possuem nível fundamental incompleto, 0,8\% fundamental completo e $0,8 \%$ ensino médio incompleto. Observa-se que a maior parte dos respondentes possuem ou estão cursando o ensino superior. 


\begin{tabular}{|l|c|c|}
\hline \multicolumn{1}{|c|}{ Nível de escolaridade } & Freqüência & Percentual (\%) \\
\hline Fundamental incompleto & 2 & 1,60 \\
\hline Fundamental completo & 1 & 0,80 \\
\hline Médio incompleto & 1 & 0,80 \\
\hline Médio completo & 43 & 34,40 \\
\hline Superior incompleto & 23 & 18,40 \\
\hline Especialista & 8 & 6,40 \\
\hline Mestre & 1 & 0,80 \\
\hline Doutor & 0 & 0 \\
\hline Total & 125 & 100 \\
\hline
\end{tabular}

Tabela 2: Nível de escolaridade dos respondentes

Fonte: Dados da pesquisa de campo, 2009

A variável relacionada ao tipo de vínculo com a Instituição (Tabela 3) revelou uma igualdade entre o número de respondentes do quadro permanente e de prestadores de serviços, ou seja, $59(47,2 \%)$. respostas de cada um. Houve ainda $0,8 \%$ de respostas de funcionários contratados por meio de empresa terceirizada e $4,8 \%$ de estagiários.

\begin{tabular}{|l|c|c|}
\hline Tipo de vínculo com a Instituição & Freqüência & Percentual (\%) \\
\hline Técnico administrativo - Quadro permanente & 59 & 47,20 \\
\hline Prestador de serviços & 59 & 47,20 \\
\hline Contrato através de empresa terceirizada & 1 & 0,80 \\
\hline Docente & 0 & 0 \\
\hline Estagiário & 6 & 4,80 \\
\hline Total & 125 & 100 \\
\hline
\end{tabular}

Tabela 3: tipo de vínculo com a Instituição

Fonte: Dados da pesquisa de campo, 2009

O tempo de serviço também foi verificado, e os dados obtidos estão representados na

Tabela 4: 


\begin{tabular}{|l|c|c|}
\hline Tempo de serviço & Frequência & Percentual (\%) \\
\hline De 00 a 05 anos & 36 & 28,80 \\
\hline De 06 a 10 anos & 32 & 25,60 \\
\hline De 11 a 15 anos & 35 & 28,00 \\
\hline De 16 a 20 anos & 9 & 7,20 \\
\hline De 21 a 25 anos & 4 & 3,20 \\
\hline Acima de 26 anos & 9 & 7,20 \\
\hline Total & 125 & 100 \\
\hline
\end{tabular}

Tabela 4: Tempo de serviço na Instituição

Fonte: Dados da pesquisa de campo, 2009

O Gráfico 2 representa a distribuição dos respondentes por centro de custo. Foram obtidas respostas de funcionários de 14 centros de custo, além de 13,6\% dos questionários que não tiveram o centro de custo informado. O HUB foi o centro de custo com maior número de respondentes, com $14,40 \%$. Isto se deve ao fato de que todos os questionários distribuídos neste centro de custo retornaram respondidos e não por um maior número de questionários aplicados.

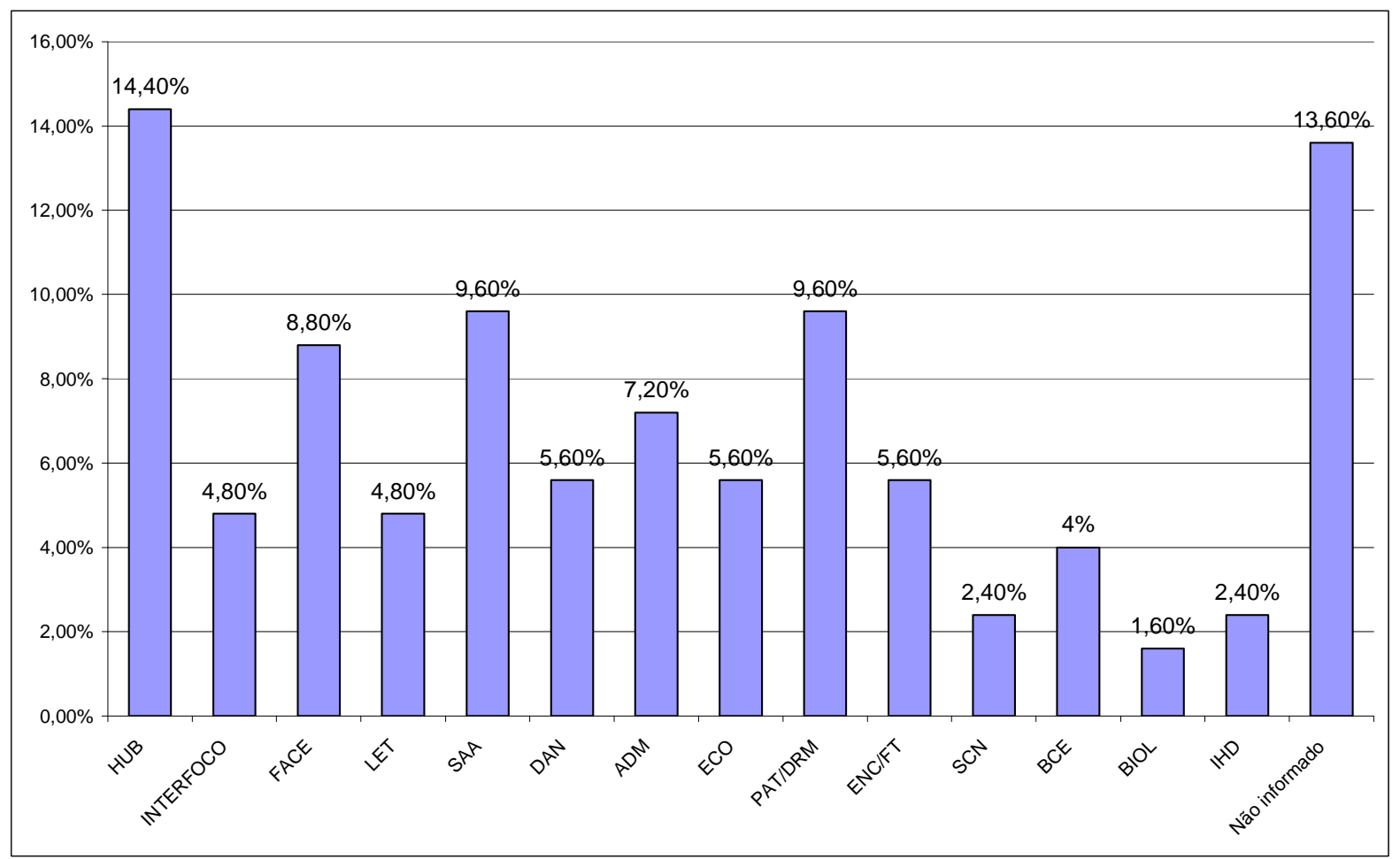

Grágico 2: Distribuição por Centro de Custo

Fonte: Dados da pesquisa de campo, 2009 
Conforme demonstraram os dados, o perfil dos respondentes foi composto por uma maioria de mulheres, com predomínio da faixa etária em torno dos 30 anos, divididos igualmente entre profissionais do quadro efetivo e prestadores de serviços da UnB, a maior parte com tempo de serviço na instituição acima de seis anos. Os dados revelaram ainda um elevado grau de escolaridade dos participantes. Dados da Pesquisa Nacional por Amostra de Domicílios (PNAD) realizada em 2007 pelo IBGE confirma uma tendência de aumento no nível de escolaridade da população brasileira em comparação com a pesquisa realizada em 2004.

\section{2 - Avaliação dos gaps da qualidade dos serviços estudados}

A aplicação do modelo SERVQUAL permitiu avaliar a qualidade dos serviços por meio da aplicação de questionários que abrangeram as cinco dimensões da qualidade (tangibilidade, confiabilidade, presteza, segurança e empatia). Desta forma, a obtenção dos dados do questionário em duas fases, onde as cinco dimensões propostas foram contempladas em 20 itens cada fase, permitiu conhecer as expectativas (fase 01) e as percepções (fase 02) dos usuários com relação aos serviços da SRH. Assim, a qualidade do serviço se traduz na diferença, ou gap entre a expectativa e a percepção. Conhecendo esta diferença é possível se detectarem os pontos que possam estar gerando insatisfação ao usuário, e assim, poder atender com maior qualidade. Como apresentado anteriormente, um resultado negativo desta diferença, indica que o serviço prestado supera a expectativa do usuário, ou seja, o usuário está satisfeito. Um resultado igual a zero indica que o serviço atende a expectativa do cliente, portanto, este também está satisfeito. Já um resultado positivo desta diferença, indica que o serviço está abaixo da expectativa, ou seja, o usuário está insatisfeito ou parcialmente satisfeito.

Segundo Miguel e Salomi (2004), “as dimensões da qualidade representam os pontos críticos na prestação de um serviço, que podem causar a discrepância entre expectativa e desempenho, que devem ser minimizadas a fim de se alcançar um padrão adequado de qualidade". Neste trabalho foi dado ênfase ao gap 5 que, segundo Cobra (2001 apud VEIGA; FARIAS, 2005) reflete as diferenças entre as expectativas do usuário, ou seja, o serviço que ele considera ideal e a sua percepção do que está sendo oferecido. Miranda; Pinto e Amaral (2002, p. 42) afirmam que no gap 5 "a qualidade percebida de um serviço depende do tamanho da lacuna entre o serviço esperado e o percebido, que, por outro lado, depende da 
intensidade dos demais gaps." A seguir serão analisadas as cinco dimensões isoladamente, detalhando ponto a ponto os dados obtidos nesta pesquisa.

\subsection{1 - Aspectos Tangíveis}

Entre os aspectos tangíveis, verificou-se a expectativa com relação às instalações físicas, os equipamentos, a localização e a quantidade de colaboradores. Segundo Berry e Parasuraman, (1992), estudos demonstram que dentre as cinco dimensões estudas, a tangibilidade é a que apresenta o menor grau de importância do ponto de vista dos usuários. Porém, como foi visto anteriormente, a visão do usuário sobre a qualidade é uma visão global, o que faz com que uma insatisfação com algum destes itens possa levar a uma percepção negativa com relação ao serviço.

Conforme apresentado na Tabela 5, as expectativas obtiveram médias entre 5 (Bem importante) e 6 (Muito importante) de acordo com a escala aplicada, sendo o maior valor $(6,080)$, obtido no item "quantidade suficiente de colaboradores para atendimento" e o menor valor $(5,528)$ relacionado às instalações físicas. As médias relacionadas à percepção estiveram todas em 4,00, que significa, pela escala aplicada, que o serviço é bom. Dentre as médias obtidas pela percepção, a maior foi verificada no item direcionado à presença de equipamentos modernos para o atendimento $(4,424)$ e a menor $(4,104)$ obtida no item instalações físicas. Todos os gaps encontrados apresentaram valor positivo, destaque para o item relacionado à quantidade de colaboradores que obteve gap 1,928. Pode-se concluir que, apesar dos usuários considerarem o serviço prestado "bom”, ele ainda está aquém de suas expectativas.

\begin{tabular}{|l|l|c|c|c|}
\hline & \multicolumn{1}{|c|}{ DIMENSÃO } & \multicolumn{3}{c|}{ MÉDIA } \\
\hline & \multicolumn{1}{|c|}{ TANGIBILIDADE } & EXPECTATIVA & PERCEPÇÃO & GAP \\
\hline $\mathbf{A}$ & $\begin{array}{l}\text { Instalações físicas adequadas (confortáveis, } \\
\text { arejadas, limpas, iluminadas e silenciosas). }\end{array}$ & $\mathbf{5 , 5 2 8}$ & $\mathbf{4 , 1 0 4}$ & $\mathbf{1 , 4 2 4}$ \\
\hline $\mathbf{B}$ & $\begin{array}{l}\text { Equipamentos modernos que possam facilitar } \\
\text { o processo de atendimento }\end{array}$ & $\mathbf{5 , 8 3 2}$ & $\mathbf{4 , 4 2 4}$ & $\mathbf{1 , 4 0 8}$ \\
\hline $\mathbf{C}$ & $\begin{array}{l}\text { Localização dos Postos avançados de } \\
\text { atendimento adequada às necessidades }\end{array}$ & $\mathbf{5 , 6 0 8}$ & $\mathbf{4 , 2 7 2}$ & $\mathbf{1 , 3 3 6}$ \\
\hline $\mathbf{D}$ & $\begin{array}{l}\text { Quantidade suficiente de colaboradores para } \\
\text { atendimento }\end{array}$ & $\mathbf{6 , 0 8 0}$ & $\mathbf{4 , 1 5 2}$ & $\mathbf{1 , 9 2 8}$ \\
\hline
\end{tabular}

Tabela 5: Médias obtidas na dimenção tangibilidades Fonte: Dados da pesquisa de campo, 2009 


\subsection{2 - Confiabilidade}

Neste aspecto foram abordados os itens referentes à capacidade de esclarecer dúvidas, à atualização das informações, ao cumprimento dos serviços a que se propõe e ao atendimento dentro do prazo determinado. Estudos demonstram que a dimensão confiabilidade é o aspecto mais importante de acordo com os usuários (BERRY; PARASURAMAN, 1992). Ainda segundo estes autores, "a confiabilidade é a essência da qualidade do serviço, que por sua vez, é a base da excelência do marketing de serviços" (p.30).

Conforme demonstrado na Tabela 6, as médias das expectativas do usuário obtiveram valor próximo de 6 , considerado de acordo com a escala, muito importante. Já de acordo com as percepções, os valores situaram-se entre 4 (bom) e 5 (muito bom). O item "cumprimento do serviço a que se propõe" apresentou a melhor média $(5,160)$ de acordo com a percepção dos usuários. Os gaps encontrados nesta dimensão foram todos positivos, refletindo que o serviço ainda precisa melhorar para atender à expectativa dos usuários. Os dados obtidos demonstraram ainda que a maior insatisfação, do ponto de vista dos respondentes, está relacionada ao atendimento das solicitações dentro do prazo, com gap de 1,448. Apesar de os respondentes considerarem o serviço prestado bom ou muito bom, ainda há espaço para melhorias, para buscar a excelência no atendimento, para atender plenamente as expectativas. Segundo Berry (1996) "um serviço excelente significa servir. É definir metas mutuamente benéficas e manter a confiança durante a jornada em direção a essas metas".

\begin{tabular}{|c|c|c|c|c|}
\hline & DIMENSÃO & \multicolumn{3}{|c|}{ MÉDIA } \\
\hline & CONFIABILIDADE & EXPECTATIVA & PERCEPÇÃO & GAP \\
\hline $\mathbf{A}$ & $\begin{array}{l}\text { Capacidade do atendente em esclarecer } \\
\text { dúvidas }\end{array}$ & 6,296 & 4,984 & 1,312 \\
\hline B & Atualização das informações prestadas & 6,312 & 5,064 & 1,248 \\
\hline $\mathbf{C}$ & Cumprimento do serviço a que se propõe & 6,376 & 5,160 & 1,216 \\
\hline D & $\begin{array}{l}\text { Atendimento das solicitações dentro de um } \\
\text { prazo determinado }\end{array}$ & 6,376 & 4,928 & 1,448 \\
\hline
\end{tabular}

Tabela 6: Médias obtidas na dimensão confiabilidade

Fonte: Dados da pesquisa de campo, 2009

\subsection{3 - Presteza}

Nesta dimensão foram pesquisados itens que verificaram a preocupação da organização em facilitar o acesso dos usuários ao serviço, ou seja, terem suas necessidades 
atendidas prontamente e com agilidade. Foram abordados o horário disponível para atendimento, o tempo para atendimento, o acesso aos serviços oferecidos e a divulgação das informações. A Tabela 7 apresenta as médias obtidas após o tratamento dos dados. É possível observar que a média das expectativas está em torno de 6 , ou seja, os usuários consideram todos os itens muito importantes. Já de acordo com a percepção, o serviço oferecido obteve média entre 4 (bom) e 5 (muito bom). Analisando os gaps obtidos, verificamos que o maior, ou seja, o resultado que está mais longe de atingir a expectativa do usuário nesta dimensão, foi relacionado à divulgação das informações, 1,416 e o menor relacionado ao horário de atendimento, com gap 1,016.

Os serviços oferecidos relacionados à presteza estão abaixo da expectativa dos respondentes, indicando que serão necessárias ações no sentido de diminuir esta diferença entre a expectativa e percepção, com atenção especial para a divulgação das informações, que apresentou o maior descontentamento. Os dados mostram que as pessoas desejam estar bem informadas sobre os assuntos de seu interesse, além de disporem de pouco tempo para esclarecer e resolver seus problemas. O resultado obtido no item "divulgação de todas as informações e atualizações de interesse do servidor" indica que os usuários percebem deficiência na comunicação, que pode estar levando a uma grande insatisfação, o que torna um importante fator a ser trabalhado pela SRH/UnB. Segundo Berry e Parasuraman (1992), uma comunicação periódica com os usuários faz com que muitos problemas sejam evitados, sendo uma forma eficaz de cuidar de suas expectativas. Isto pode aumentar o nível de satisfação.

\begin{tabular}{|c|c|c|c|c|}
\hline & DIMENSÃO & \multicolumn{3}{|c|}{ MÉDIA } \\
\hline & PRESTEZA & EXPECTATIVA & PERCEPÇÃO & GAP \\
\hline $\mathbf{A}$ & $\begin{array}{l}\text { Horário de atendimento adequado às } \\
\text { necessidades do usuário }\end{array}$ & 6,024 & 5,008 & 1,016 \\
\hline B & Tempo para atendimento & 5,920 & 4,760 & 1,160 \\
\hline $\mathbf{C}$ & $\begin{array}{l}\text { Acesso aos serviços oferecidos pela SRH } \\
\text { (inclusive via internet) }\end{array}$ & 6,008 & 4,864 & 1,144 \\
\hline D & $\begin{array}{l}\text { Divulgação de todas as informações } \mathrm{e} \\
\text { atualizações de interesse do servidor }\end{array}$ & 6,256 & 4,840 & 1,416 \\
\hline
\end{tabular}

Tabela 7: Médias obtidas na dimensão presteza Fonte: Dados da pesquisa de campo, 2009 


\subsection{4 - Segurança}

Nesta dimensão, são abordadas as expectativas com relação à clareza na transmissão das informações, à segurança transmitida pelo funcionário, à organização e ao esforço que o funcionário demonstra durante o atendimento. Os resultados (Tabela 8) demonstraram que as expectativas ainda estão acima do que é percebido, ou seja, os gaps foram todos positivos. Os respondentes consideraram os itens abordados "bem importante" ou "muito importante", situando-se as médias entre 5 e 6 na escala. De acordo com a percepção, nestes aspectos, os serviços foram considerados "bom" ou "muito bom", estando as médias entre 4 e 5 respectivamente.

Nesta dimensão tem que se destacar que o valor obtido mais próximo de atingir a expectativa está relacionado ao "esforço do funcionário em prestar um bom atendimento", que obteve o menor gap $(0,712)$, indicando que os respondentes reconhecem que os funcionários se esforçam para prestar um bom atendimento. O resultado mais distante de atingir a expectativa foi obtido no item relacionado à "clareza na transmissão das informações" com gap 1,360, indicando certa dificuldade do usuário em entender as informações que são transmitidas. Mais uma vez aqui, percebem-se falhas na comunicação, o que gera insatisfação. Isto reflete a importância de uma comunicação bem feita no atendimento à expectativa dos clientes. Neste sentido, estratégias de marketing podem ser adotadas para melhorar a comunicação e consequentemente o entendimento dos usuários. Berry e Parasuraman (1992, p 85) afirmam que "comunicar-se de modo eficiente com os clientes faz com que eles se sintam apreciados e reduz ou evita a frustração quando ocorrem problemas no serviço".

\begin{tabular}{|c|c|c|c|c|}
\hline & DIMENSÃO & \multicolumn{3}{|c|}{ MÉDIA } \\
\hline & SEGURANÇA & EXPECTATIVA & PERCEPÇÃO & GAP \\
\hline A & Clareza na transmissão das informações & 6,336 & 4,976 & 1,360 \\
\hline $\mathbf{B}$ & Segurança transmitida pelo funcionário & 6,112 & 5,048 & 1,064 \\
\hline $\mathbf{C}$ & $\begin{array}{lll}\begin{array}{l}\text { Organização dos } \\
\text { desempenho da função }\end{array} & \text { funcionários } & \text { no } \\
\end{array}$ & 5,752 & 4,744 & 1,008 \\
\hline D & $\begin{array}{l}\text { Esforço do funcionário para prestar um bom } \\
\text { atendimento }\end{array}$ & 5,912 & 5,200 & 0,712 \\
\hline
\end{tabular}

Tabela 8: Médias obtidas na dimensão segurança Fonte: Dados da pesquisa de campo, 2009 


\subsection{5 - Empatia}

Segundo Kotler (2000 apud MUNDIM;AUGUST, 2008), a prática da empatia significa se colocar no lugar do cliente para avaliar suas necessidades, partindo do princípio de que cada cliente é único, com suas necessidades próprias, o que implica um atendimento diferenciado e individual. Faz-se necessário também se auto avaliar, assim é possível refletir sobre o seu próprio atendimento. Aqui foram analisados os seguintes itens: entendimento do servidor em relação a sua necessidade, atendimento individualizado, interesse em atender às solicitações e educação e gentileza dos servidores.

No aspecto empatia foram obtidos resultados bem próximos de atender à expectativa dos usuários, conforme demonstra a Tabela 9. As médias obtidas pela expectativa estão entre 5 e 6 significando que os usuários consideram o serviço bem importante ou muito importante. Já pela percepção a média de todos os itens esteve situada em 5, significando que consideram o serviço prestado muito bom. O melhor gap apresentado $(0,312)$ foi relacionado à "educação e gentileza dos servidores", com o valor do gap próximo de zero, ou seja, próximo de atender à expectativa. Ao avaliar estes dados, nota-se um fator interessante, o reconhecimento dos respondentes à atuação dos funcionários da $\mathrm{SRH}$, o que indica que as insatisfações podem estar mais ligadas às condições de que dispõem para desempenhar o trabalho. Estes resultados também só confirmam a importância referenciada de valorizar os recursos humanos, tendo em vista que os itens avaliados nesta dimensão estão diretamente relacionados ao desempenho dos funcionários.

\begin{tabular}{|l|l|c|c|c|}
\hline & \multicolumn{1}{|c|}{ DIMENSÃO } & \multicolumn{3}{c|}{ MÉDIA } \\
\hline \multicolumn{1}{|c|}{ EMPATIA } & EXPECTATIVA & PERCEPÇão & GAP \\
\hline $\mathbf{A}$ & $\begin{array}{l}\text { Entendimento do funcionário em relação à } \\
\text { necessidade do usuário }\end{array}$ & $\mathbf{5 , 8 2 4}$ & $\mathbf{5 , 1 6 8}$ & $\mathbf{0 , 6 5 6}$ \\
\hline B & Atendimento individualizado & $\mathbf{6 , 1 3 6}$ & $\mathbf{5 , 4 8 0}$ & $\mathbf{0 , 6 5 6}$ \\
\hline C & Interesse em atender às solicitações & $\mathbf{5 , 8 2 4}$ & $\mathbf{5 , 2 1 6}$ & $\mathbf{0 , 6 0 8}$ \\
\hline D & Educação e gentileza dos funcionários & $\mathbf{5 , 8 1 6}$ & $\mathbf{5 , 5 0 4}$ & $\mathbf{0 , 3 1 2}$ \\
\hline
\end{tabular}

Tabela 9: Médias obtidas na dimensão empatia

Fonte: Dados da pesquisa de campo, 2009 
Para facilitar a visualização e comparação entre os itens avaliados na pesquisa, os gaps obtidos foram representados no Gráfico 3, a seguir. Lembrando sempre que quanto maior o gap, maior o grau de insatisfação:

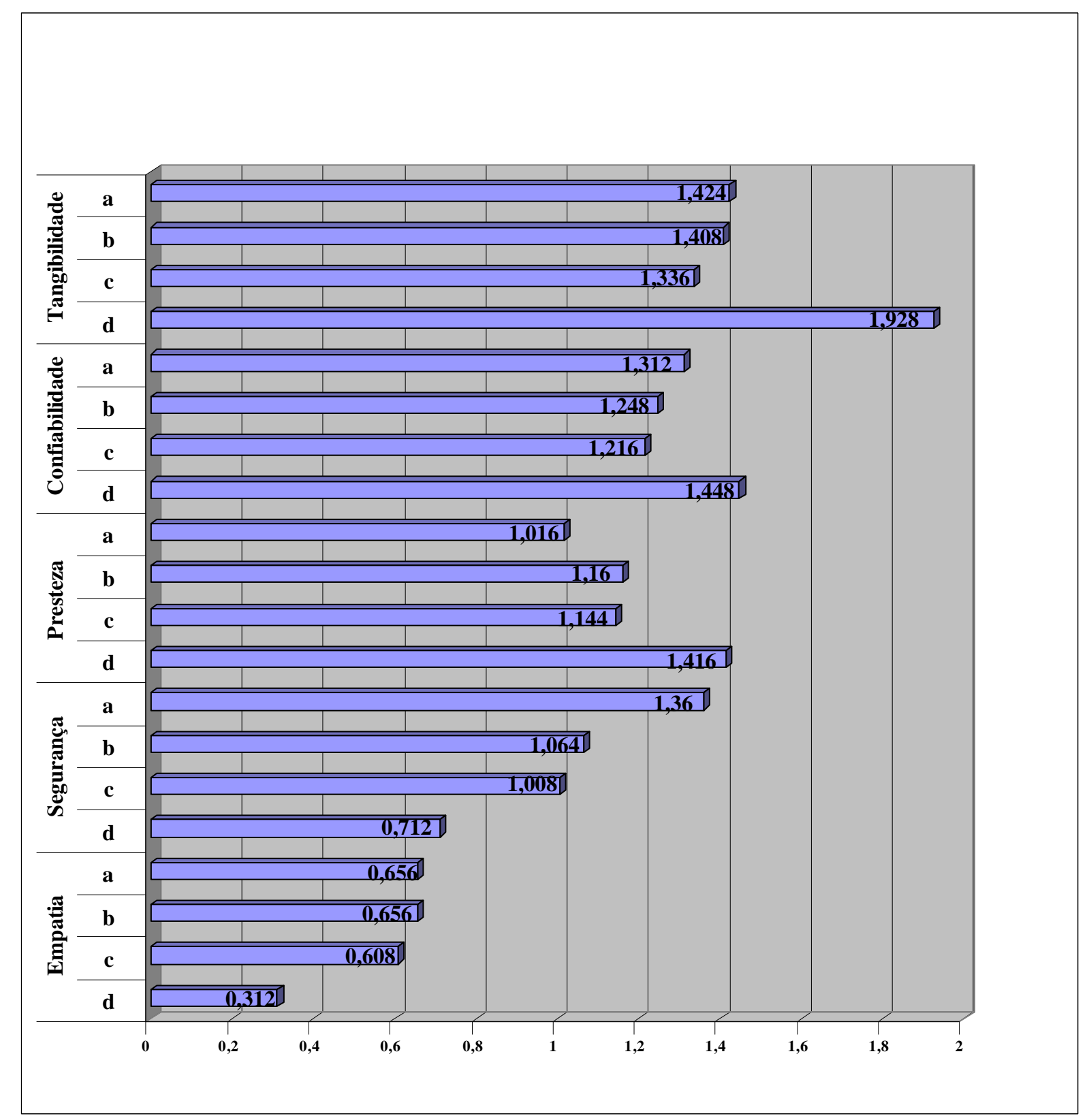

Gráfico 3: Resultado dos gaps por item.

Fonte: Dados da pesquisa de campo, 2009

Os resultados demonstram que há um grande espaço para melhoria do serviço estudado, o qual não conseguiu atingir o nível de expectativa do usuário em nenhum item pesquisado que, segundo o modelo, teriam que apresentar gap igual a zero. Os resultados sugerem ainda as áreas que, pela pesquisa, necessitariam de maior atenção, em especial os itens avaliados nas dimensões tangibilidade e confiabilidade. Os aspectos referentes aos 
profissionais foram o destaque positivo da pesquisa com valores dos gaps próximos a zero em todos os itens avaliados na dimensão empatia e no item “ $d$ ' da dimensão segurança. A seguir serão discutidos os gaps obtidos em cada dimensão.

\section{3 - Verificação dos gaps por dimensão}

Fazendo uma análise das médias obtidas em cada dimensão, é possível observar que, entre as cinco dimensões abordadas neste estudo, o melhor resultado foi obtido na dimensão empatia, que apresentou o menor gap $(0,552)$. O pior resultado encontra-se na dimensão tangibilidade, onde foi encontrado o maior gap (1,525). De maneira geral, todas as dimensões estiveram abaixo da expectativa dos respondentes. De acordo com a escala proposta, a expectativa esteve com média entre 5 e 6 , ou seja, os serviços foram considerados "bem importante" ou "muito importante" e de acordo com a percepção, a média esteve entre 4 e 5, sendo os serviços considerados "bom" ou "muito bom". Há que se destacar também o alto gap obtido pela dimensão confiabilidade, que é vista como a dimensão mais importante de acordo com pesquisas efetuadas, conforme Berry e Parasuraman (1992). É necessário que os gestores responsáveis estejam atentos a estes números, pois uma melhora nos aspectos que impactam na confiabilidade demonstrada pela instituição poderá trazer uma melhoria significativa na percepção do usuário com relação ao serviço, além de promover uma maior eficiência operacional, o que influirá também em outras dimensões avaliadas. Segundo Berry e Parasuraman (1992, p. 31),

a confiabilidade do serviço também contribui com as demais eficiências operacionais, reduzindo a necessidade de refazer o serviço. Não obstante, o custo de um serviço não-confiável inclui diretamente a despesa de refazer o serviço e também os custos indiretos das penalizações associadas à publicidade negativa gerada pelos clientes irritados.

A Tabela 10 representa os gaps por dimensão: 


\begin{tabular}{|l|c|c|c|}
\hline \multicolumn{1}{|c|}{ DIMENSÃO } & EXPECTATIVA & PERCEPÇÃO & GAPS \\
\hline TANGÍBILIDADE & $\mathbf{5 , 7 6 2}$ & 4,238 & 1,524 \\
\hline CONFIABILIDADE & 6,340 & 5,034 & 1,306 \\
\hline PRESTEZA & 6,052 & 4,868 & 1,184 \\
\hline SEGURANÇA & $\mathbf{6 , 0 2 8}$ & 4,992 & 1,036 \\
\hline EMPATIA & 5,900 & 5,342 & $\mathbf{0 , 5 5 8}$ \\
\hline
\end{tabular}

Tabela 10: Representação das médias por dimensão Fonte: Dados da pesquisa de campo, 2009

O Gráfico 4, a seguir, pode proporcionar uma boa visão a respeito dos gaps encontrados por dimensão, segundo o qual se pode concluir quais obtiveram as melhores e piores avaliações:

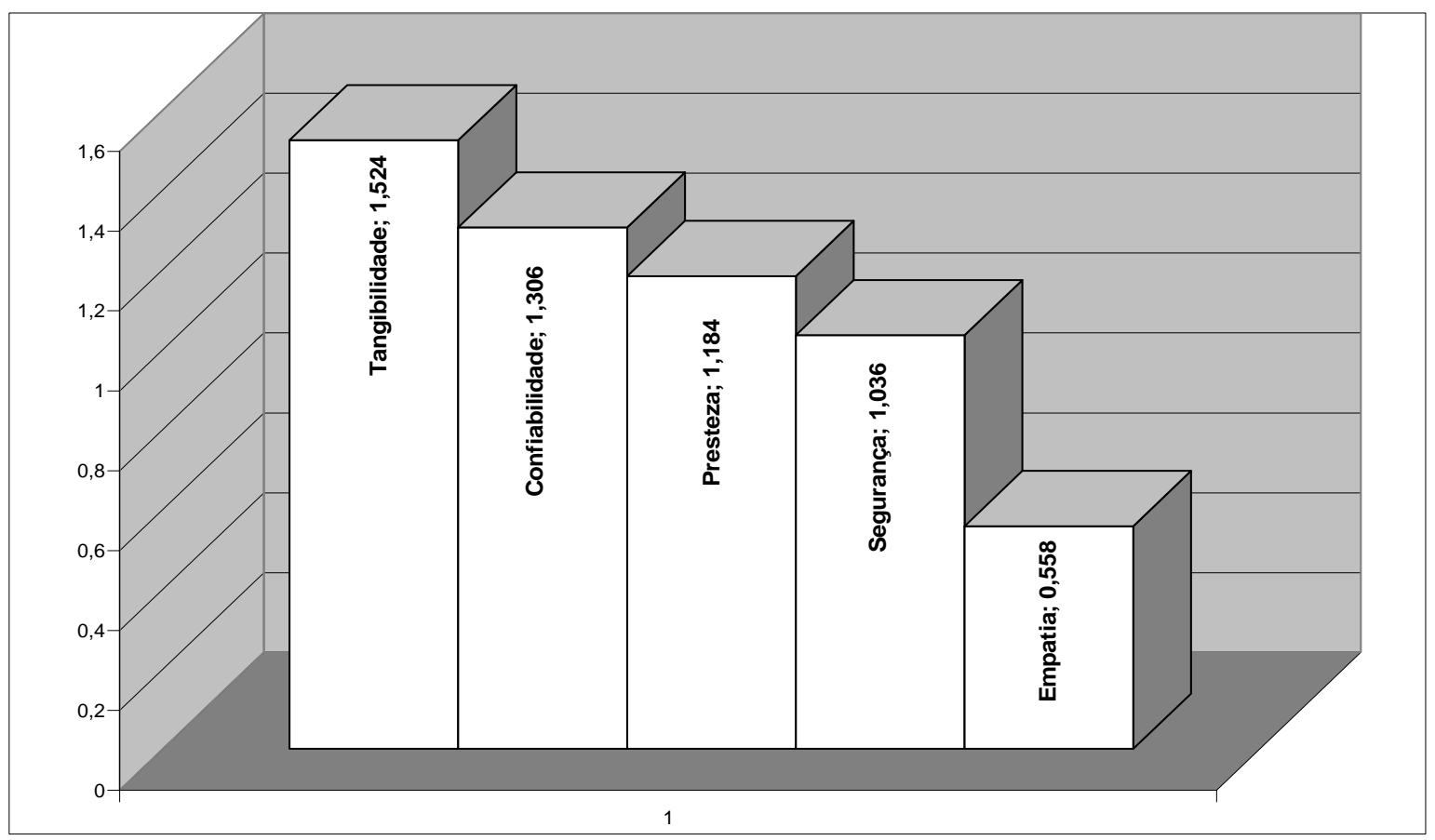

Gráfico 4: representação dos gaps por dimensão.

Fonte: Dados da pesquisa de campo 2009

A busca pela excelência deve ser uma constante. Segundo Berry (1996, p. 273),

a Excelência em serviços é uma atitude. É um esforço extra, um cuidado extra. É fazer bem as pequenas coisas, recorrendo-se a detalhes para ser diferente e lutar pela perfeição. É servir um cliente de cada vez, ouvir atentamente, interpretar o que tenha ou não sido dito, e achar uma forma de fornecer valor, achar uma forma de agradar o cliente, na hora. 
Portanto, os dados obtidos com as pesquisas de opiniões devem ser vistos como oportunidades de melhoria, e não somente como críticas ao serviço. É importante estabelecer meios de trabalhar as pequenas falhas, os pequenos detalhes que possam estar impactando negativamente no serviço prestado, buscando alternativas no sentido de minimizá-los ou até mesmo eliminá-los definitivamente. Dessa forma, pode-se melhorar a qualidade do serviço como um todo, consequentemente aumentando a satisfação dos usuários e também dos funcionários. 


\section{CONSIDERAÇÕES FINAIS}

A presente pesquisa estudou a qualidade dos serviços prestados pela Secretaria de Recursos Humanos da Universidade de Brasília do ponto de vista dos usuários respondentes dos questionários, que são funcionários e em alguns casos, estagiários da instituição. Apresentou como objetivos identificar as expectativas e percepções deles com relação aos serviços além de identificar a lacuna existente, chamada neste estudo de gap, entre o que é esperado, ou seja, o que consideram importante para que a prestação deste serviço atenda às suas expectativas, e o que percebem do serviço que é prestado atualmente.

O estudo foi baseado em cinco dimensões da qualidade: tangibilidade, confiabilidade, presteza, segurança e empatia. Vários aspectos foram estudados para que se pudesse fundamentar o estudo e com isso atingir os objetivos propostos. Podem-se destacar os aspectos relacionados ao marketing, à qualidade dos serviços, além do conceito de serviços.

Ficou claro o aspecto essencialmente intangível quando se fala em prestação de serviços. O que o cliente está buscando não é um objeto, mas o próprio desempenho da instituição que presta o serviço. Isto traz um aspecto muito subjetivo ao trabalho, pois, a forma como um usuário percebe determinada situação pode ser completamente diferente de outro. Por isso, atingir um nível elevado de excelência, com um padrão de qualidade que atenda ou supere as expectativas do usuário deve se tornar uma busca constante, com planos estratégicos bem feitos, baseados principalmente na necessidade daqueles que utilizam o serviço.

Os resultados obtidos na pesquisa demonstraram que os serviços prestados pela $\mathrm{SRH} / \mathrm{UnB}$ apresentaram uma boa avaliação por parte dos respondentes, porém, ainda não atingiram o nível de expectativas dos usuários. Os aspectos relacionados à dimensão tangibilidade foram os que apresentaram os piores resultados, seguido pelo aspecto confiabilidade. Demonstrou-se que os usuários carecem de ambientes mais confortáveis e de serviços que possam despertar total confiança, com melhora na transmissão das informações e serviços realizados dentro do esperado e também de um prazo previamente determinado.

Um grande aspecto positivo a se destacar foram os resultados obtidos com relação ao desempenho dos funcionários da $\mathrm{SRH} / \mathrm{UnB}$, principalmente na dimensão empatia, que foi a que esteve mais próxima de atingir as expectativas dos usuários dentre todas as dimensões avaliadas. Também foi encontrado um bom resultado no item avaliado na dimensão segurança, que diz respeito ao esforço do funcionário em prestar um bom serviço, estando bem próximo de atender as expectativas dos usuários. 
A qualidade na prestação de serviço demonstrou ser um tema que merece muita atenção, principalmente no que diz respeito ao serviço público. Parte da reflexão feita no capítulo teórico do trabalho mostrou que o próprio Governo Federal está cada vez mais empenhado em melhorar a qualidade dos serviços prestados pelas instituições públicas, principalmente para tentar mudar a imagem de que serviço público é sinônimo de mau serviço. Prova disso é a criação do programa GesPública que busca aumentar a competitividade do serviço público com melhora na qualidade.

Por fim deve-se destacar a contribuição que a escala SERVQUAL, utilizada na pesquisa, é capaz de proporcionar no sentido de medir realmente até que ponto a qualidade do serviço ofertado corresponde à expectativa do usuário. Pois, se simplesmente avaliasse a percepção do desempenho, provavelmente os resultados seriam bem diferentes e não demonstrariam o grau de expectativas que o usuário carrega consigo quando precisa fazer uso de serviços. Se a qualidade de um serviço é demonstrada também pelos usuários, então se torna de grande importância que se estabeleçam meios para ouvir as suas opiniões. 


\section{REFERÊNCIAS}

ALBRECHT, K. A revolução dos serviços: como as empresas podem revolucionar a maneira de tratar os seus clientes. 4. ed. São Paulo: Pioneira, 1994a.

Serviços internos: como resolver a crise de liderança do gerenciamento de nível médio. São Paulo: Pioneira, 1994b.

AMARAL, P. A.; PINTO, W. G.; MIRANDA, A. L. Como gerenciar as expectativas na prestação de serviços. Cadernos discentes COPPEAD, Rio de Janeiro, n.11, p. 28-53, 2002.

BERRY, L.L. Serviços de Satisfação Máxima: guia prático de ação. Trad. Bazan Tecnologia e Lingüística. Rio de Janeiro: Campus, 1996.

BERRY, L.L.; PARASURAMAN, A. Serviços de Marketing: competindo através da qualidade. Trad. Beatriz Sidou. São Paulo: Maltese-Norma, 1992.

BITTENCOURT, R. J.; HORTALE, V. A. A qualidade nos serviços de emergência de hospitais públicos e algumas considerações sobre a conjuntura recente no município do Rio de Janeiro. Ciência e Saúde coletiva, vol. 12, nº 4, Rio de Janeiro, jul./ago.2007

BRASIL. Constituição da República Federativa do Brasil, 5 de outubro de 1988. 17.ed. São Paulo: Atlas; 1988.

BRASIL, Ministério do Planejamento, Orçamento e Gestão. Portal Gestão Pública. Disponível em https://conteudo.gespublica.gov.br/menu_principal/gespublica/folder.2007-0321.2806316778, acessado em 21 de abril de 2009 .

BRASIL, Ministério do Planejamento, Orçamento e Gestão, Instituto Brasileiro de Geografia e Estatística, Pesquisa Nacional por Amostra de Domicílios, v.28, p. 1-129, Disponível em http://www.ibge.gov.br/home/estatistica/populacao/trabalhoerendimento/pnad2007/brasilpnad 2007.pdf, acessado em 28 de abril de 2009.

BRASIL, Portal da Universidade de Brasília: Secretaria de Recursos Humanos. Disponível em http://www.srh.unb.br/ Acessado em: 24/04/2009.

COBRA, M.; ZWARG, F. A. Marketing de Serviços: Conceitos e Estratégias. São Paulo: McGraw-Hill, 1986.

CUNHA, M. V. M; BORGES Jr. A. A.; FACHEL, J. M. G. Esquema CBF para mensuração da satisfação de clientes: um a proposta conceitual e prática. Anais Dio XXII. ENANPAD/Marketing, 1998. 
CUNHA, N. R. S. Avaliação da qualidade de serviços percebida utilizando a escala Servqual: o estudo de caso da PRODABEL. In XXIV Encontro Nac. de Eng. de Produção - Florianópolis, SC, Brasil, 03 a 05 de nov de 2004.

DETTMER, B.; SOCORRO, C.; KATON, H. T. Marketing de serviços - análise da percepção da qualidade de serviços através da ferramenta SERVQUAL em uma instituição de ensino superior de Santa Catarina, Revista de Ciências da Administração, v. 4, $\mathrm{n}^{\circ} 08$, jul/dez 2002.

DIEHL, A. A.; TATIM, D.C. Pesquisa em ciências sociais aplicadas: métodos e técnicas. São Paulo: Prentice Hall, 2004.

DOMINGUES, M. E. M.; ALLIPANDRINE, D. H. Avaliação dos determinantes da qualidade em serviços de instituições hospitalares. In: Encontro Nacional de Engenharia de Produção, 23., 1998, Niterói.

ESPERIDIÃO, M.; TRAD, L. A. B. Avaliação de satisfação de usuários. Ciência e Saúde Coletiva, 10(sup): p.303-312, 2005.

FERREIRA, M. C. Serviço de Atendimento ao Público: O que é? Como analisá-lo? Esboço de uma Abordagem Teórico-Metodológica em Ergonomia, Revista Multitemas, $\mathrm{n}^{\circ}$ 16, maio, 2000, pp. 128-144, Campo Grande-MS, UCDB.

GIANESI, I. G. N; CORRÊA, H. L. Administração estratégica de serviços: operações para a satisfação do cliente. São Paulo: Atlas, 1994.

KOTLER, P. Administração de marketing: análise, planejamento, implementação e controle. São Paulo; Atlas, 1996

Administração de marketing: a edição do novo milênio. São Paulo: Prentice Hall, 2001.

LAS CASAS, A. L. Marketing: conceitos, exercícios, casos. 4. ed. São Paulo: Atlas, 1997.

LIMA, S. P. da S.; SILVA, A. K. A. O bibliotecário e o marketing pessoal na biblioteca do unipê: instrumento de promoção profissional no mercado de trabalho, Biblionline, João pessoa, v. 3, n.1, 2007

LOVELOCK C.; WRIGHT, L. Serviços Marketing e Gestão. 3. ed. São Paulo: Saraiva, 2003.

MALIK, A. M. Gestão de Recursos Humanos. v. 9 São Paulo: Faculdade de Saúde Pública da Universidade de São Paulo, 1998 (série Saúde e Cidadania).

MEIRELLES, H. L. Direito Administrativo Brasileiro. 19. ed. São Paulo: Malheiros, 1994. 
MIGUEL, P. A. C.; SALOMI, G. E. Uma revisão dos modelos para medição da qualidade em serviços. Revista Produção v. 14 no 1, 2004.

MOURA, A. L. N. de; SOUZA, B. C. Analisando o impacto da consultoria interna no setor público, Revista Economia e Gestão, v. 8, n 18, 2008.

MUNDIM, R. S. A.; AUGUST, D. R. Análise de gaps da qualidade no pós-venda da concessionária Le Monde Citroen - Blumenau. Revista Interdisciplinar Científica Aplicada, Blumenau, v.2, n 2, p.01-28, Sem I. 2008

NASCIMENTO, R. B.; TROMPIERI FILHO, N.; BARROS, F. G. F. Avaliação da qualidade dos serviços prestados nas unidades de informação universitárias. Transinformação, Campinas, v.17, n.3, p. 235-251, set./dez., 2005.

NOGUEIRA, A. E. S. R. A percepção da qualidade de serviços aplicada em uma instituição de ensino superior. 2004. Dissertação (Mestrado profissional em Engenharia Mecânica/Qualidade Total) - UNICAMP, Campinas-SP, 2004.

PEREIRA, A. T.; FARIAS, J. S. Avaliação da Qualidade dos Serviços prestados por um empreendimento hoteleiro: um caso estudado no litoral sergipano. In: XI Seminário de Pesquisa do CCSA/UFRN, 22 a 26/ago/2005.

RAMOS, A. C. D., Qualidade no serviço público em municípios lindeiros ao Lago de Itaipu, segundo o Programa de Qualidade no Serviço Público (PQSP 2003). 2004. Dissertação (Mestrado em Administração: Gestão Moderna de Negócios) - Universidade Regional de Blumenau, Blumenau-SC, 2004.

Resolução do Conselho de Administração N. 9/2008 da Fundação Universidade de Brasília. Disponível em: http://www.srh.unb.br/extra/organograma/gedef/resolucao_cad_9_08.pdf acessado em 06 de dezembro de 2008.

SABINO, A. G. Estabelecimento de conjunto de indicadores de desempenho para suprir as exigências da Norma ISO 9001 versão 2000. 2004. Dissertação (Mestrado profissional em Engenharia - Modalidade Profissionalizante - Ênfase em Qualidade e Desenvolvimento de Produtos e Processos) - Universidade Federal do Rio Grande do Sul, Porto Alegre - RS, 2004.

SAMARA, B. S. Pesquisa de marketing: conceitos e metodologia, 3. Ed. São Paulo: Pearson Pretice Hall, 2002.

SILVA, M. M. A. Dicionário terminológico da gestão pela qualidade total em serviços. 2003. 604 f. Tese (Doutorado em Letras: Filologia e Língua Portuguesa) - Universidade de São Paulo, São Paulo, 2003.

VEIGA, L. S.; FARIAS, J. S. Avaliação da qualidade dos serviços em uma pousada com a aplicação da escala Servqual. Turismo - Visão e Ação, v.7, n.2, p. 257-272, maio/ago., 2005.

VERGARA, S. C. Começando a definir a metodologia. In: pesquisa em Administração. 3. ed. São Paulo: Atlas, 2000. cap.4, p.46-53. 


\section{APÊNDICE A: Instrumento utilizado para coleta de dados.}

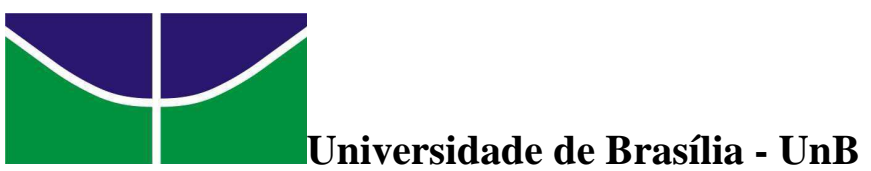

\section{Faculdade de Economia, Administração, Contabilidade e Ciência da Informação e Documentação - FACE \\ Curso de Pós-Graduação Lato Sensu em Gestão Universitária}

Prezado(a) Servidor(a):

Solicito a sua colaboração no sentido de responder ao questionário a seguir, emitindo sua opinião quanto dos serviços prestados pela Secretaria de Recursos Humanos da Universidade de Brasília (SRH/UnB).

Este questionário serve como instrumento de coleta de dados para uma pesquisa de monografia de conclusão do Curso Gestão Universitária que se propõe a avaliar a qualidade dos serviços prestados pela SRH/UnB sob a visão dos servidores desta Instituição.

A pesquisa é composta de 02 fases:

$1^{\text {a }}$ Fase: avaliará a sua expectativa com relação aos serviços prestados pela $\mathrm{SRH} / \mathrm{UnB}$, ou seja, o que você considera que seria um atendimento ideal;

$2^{\text {a }}$ Fase: avaliará a sua percepção quanto aos serviços que são oferecidos atualmente pela $\mathrm{SRH} / \mathrm{UnB}$.

Esclarecemos que por questões éticas, manteremos sigilo absoluto dos dados coletados, os quais serão apresentados de forma agrupada, impossibilitando a identificação dos respondentes.

Obrigado pela sua participação!

Aluísio Xavier de M. Brasil

Téc. Laboratório-HUB/UnB

Aluno Pesquisador 


\section{Fase 1 - Avaliacão de expectativa em relacão aos serviços da SRH/UnB}

INSTRUCÕES: classifique as afirmativas a seguir de acordo com suas expectativas com relação à SRH/UnB. Para cada item, pedimos a gentileza de marcar com um $\mathrm{X}$ o grau de importância em relação à afirmativa. Caso você considere a afirmativa extremamente importante marque a opção "7" (sete), caso não considere importante, marque a opção "1"(um). Se sua opinião estiver numa posição intermediária na escala, marque a opção que melhor represente aquilo que você pensa ou sente, seguindo a classificação da escala de opinião a seguir:

\begin{tabular}{|c|c|c|c|c|c|c|}
\hline \multicolumn{7}{|c|}{ Classificação da Escala de Opinião (o que é importante) } \\
\hline $\begin{array}{c}\text { Não é } \\
\text { importante }\end{array}$ & $\begin{array}{c}\text { Pouco } \\
\text { importante }\end{array}$ & $\begin{array}{c}\text { Relativamente } \\
\text { importante }\end{array}$ & Importante & $\begin{array}{c}\text { Bem } \\
\text { importante }\end{array}$ & $\begin{array}{c}\text { Muito } \\
\text { importante }\end{array}$ & $\begin{array}{c}\text { Extremamente } \\
\text { importante } \\
\text { (imprescindível) } \\
\mathbf{1}\end{array}$ \\
$\mathbf{2}$ & $\mathbf{3}$ & $\mathbf{4}$ & $\mathbf{5}$ & $\mathbf{6}$ & $\mathbf{7}$ \\
\hline
\end{tabular}

\begin{tabular}{|c|c|c|c|c|c|c|c|c|}
\hline \multicolumn{2}{|r|}{$\begin{array}{l}\text { De acordo com sua EXPECTATIVA, emita sua opinião utilizando a escala de } 01 \text { a } 07 \\
\text { com relação aos aspectos que se seguem referentes à SRH/UnB: }\end{array}$} & \multirow{2}{*}{\multicolumn{7}{|c|}{ Escala de opinião }} \\
\hline \multicolumn{2}{|r|}{ Aspectos Tangíveis: } & & & & & & & \\
\hline a) & Instalações físicas adequadas (confortáveis, arejadas, limpas, iluminadas e silenciosas). & \begin{tabular}{l|l}
1 & 2 \\
\end{tabular} & 3 & 4 & 5 & & & \\
\hline b) & Equipamentos modernos que possam facilitar o processo de atendimento & \begin{tabular}{l|l}
1 & 2 \\
\end{tabular} & 3 & 4 & 5 & & 6 & 7 \\
\hline c) & Localização dos Postos avançados de atendimento adequada às necessidades & \begin{tabular}{l|l}
1 & 2 \\
\end{tabular} & 3 & 4 & 5 & & 6 & 7 \\
\hline d) & Quantidade suficiente de colaboradores para atendimento & \begin{tabular}{l|l|l}
1 & 2 \\
\end{tabular} & 3 & 4 & 5 & & 6 & 7 \\
\hline \multicolumn{2}{|r|}{ Confiabilidade: } & \multicolumn{7}{|c|}{ Escala de opinião } \\
\hline a) & Capacidade do atendente em esclarecer dúvidas & 12 & 3 & 4 & 5 & & $\frac{100}{6}$ & 7 \\
\hline b) & Atualização das informações prestadas & \begin{tabular}{l|l|l}
1 & 2 \\
\end{tabular} & 3 & 4 & 5 & & 6 & 7 \\
\hline c) & Cumprimento do serviço a que se propõe & 1 & 3 & 4 & 5 & & 6 & 7 \\
\hline d) & Atendimento das solicitações dentro de um prazo determinado & \begin{tabular}{l|l}
1 & 2 \\
\end{tabular} & 3 & 4 & 5 & & & 7 \\
\hline \multicolumn{2}{|r|}{ Presteza: } & \multicolumn{7}{|c|}{ Escala de opinião } \\
\hline a) & Horário de atendimento adequado às necessidades do usuário & \begin{tabular}{l|l|l}
1 & 2 \\
\end{tabular} & 3 & 4 & 5 & & 6 & 7 \\
\hline b) & Tempo para atendimento & 1 & 3 & 4 & 5 & & 6 & 7 \\
\hline c) & Acesso aos serviços oferecidos pela SRH (inclusive via internet) & 1 & 3 & 4 & 5 & & 6 & 7 \\
\hline d) & Divulgação de todas as informações e atualizações de interesse do servidor & \begin{tabular}{l|l}
1 & 2 \\
\end{tabular} & 3 & 4 & 5 & & 6 & 7 \\
\hline \multicolumn{2}{|r|}{ Segurança: } & \multicolumn{7}{|c|}{ Escala de opinião } \\
\hline a) & Clareza na transmissão das informações & $1 \mid 2$ & 3 & 4 & & & 6 & 7 \\
\hline b) & Segurança transmitida pelo funcionário & 1 & 3 & 4 & 5 & & 6 & 7 \\
\hline c) & Organização dos funcionários no desempenho da função & 1 & 3 & 4 & 5 & & 6 & 7 \\
\hline d) & Esforço do funcionário para prestar um bom atendimento & \begin{tabular}{l|l|l}
1 & 2 \\
\end{tabular} & 3 & 4 & & & 6 & 7 \\
\hline \multicolumn{2}{|r|}{ Empatia } & \multicolumn{7}{|c|}{ Escala de opinião } \\
\hline a) & Entendimento do funcionário em relação à necessidade do usuário & $1 \mid 2$ & 3 & 4 & 5 & & 6 & 7 \\
\hline b) & Atendimento individualizado & \begin{tabular}{l|l}
1 & 2 \\
1 &
\end{tabular} & 3 & 4 & 5 & & 6 & 7 \\
\hline c) & Interesse em atender às solicitações & \begin{tabular}{l|l}
1 & 2
\end{tabular} & 3 & 4 & 5 & & 6 & 7 \\
\hline d) & Educação e gentileza dos funcionários & \begin{tabular}{l|l}
1 & 2
\end{tabular} & 3 & 4 & 5 & & 6 & 7 \\
\hline
\end{tabular}




\section{Fase 02: Avaliacão da percepcão dos servicos prestados pela SRH/UnB}

INSTRUCÕES: De acordo com sua percepção, classifique os serviços oferecidos pela SRH/UnB conforme as afirmativas a seguir. Para cada item, pedimos a gentileza de marcar com um X o seu grau de satisfação em relação à afirmativa. Caso você considere que o serviço oferecido é excelente marque a opção "7"(sete), caso considere o serviço péssimo, marque a opção "1" (um). Se sua opinião estiver numa posição intermediária na escala, marque a opção que melhor represente aquilo que você pensa ou sente, seguindo a classificação da escala de opinião a seguir:

\begin{tabular}{|c|c|c|c|c|c|c|}
\hline \multicolumn{7}{|c|}{ Classificação da Escala de Opinião (Qualidade dos serviços) } \\
\hline $\begin{array}{c}\text { Péssimo (não } \\
\text { atende às } \\
\text { expectativas) } \\
\mathbf{1}\end{array}$ & Ruim & Regular & Bom & Muito Bom & Ótimo & $\begin{array}{c}\text { Excelente (atende } \\
\text { plenamente às } \\
\text { expectativas) } \\
\text { (1) }\end{array}$ \\
\hline
\end{tabular}

\begin{tabular}{|c|c|c|c|c|c|c|c|c|c|}
\hline \multirow{2}{*}{\multicolumn{2}{|c|}{$\begin{array}{l}\text { De acordo com sua PERCEPÇÃO, emita sua opinião utilizando a escala de } 01 \text { a } 07 \mathrm{com} \\
\text { relação aos aspectos que se seguem referentes à SRH/UnB: } \\
\text { Aspectos Tangíveis: }\end{array}$}} & \multirow{2}{*}{\multicolumn{8}{|c|}{ Escala de opinião }} \\
\hline & & & & & & & & & \\
\hline a) & Instalações físicas adequadas (confortáveis, arejadas, limpas, iluminadas e silenciosas). & & 2 & 3 & 4 & 5 & 6 & & 7 \\
\hline b) & Equipamentos modernos que possam facilitar o processo de atendimento & 1 & 2 & 3 & 4 & 5 & 6 & & 7 \\
\hline c) & Localização dos Postos avançados de atendimento adequada às necessidades & 1 & 2 & 3 & 4 & 5 & 6 & & 7 \\
\hline d) & Quantidade suficiente de colaboradores para atendimento & 1 & 2 & 3 & 4 & 5 & 6 & & 7 \\
\hline \multicolumn{2}{|c|}{ Confiabilidade: } & \multicolumn{8}{|c|}{ Escala de opinião } \\
\hline a) & Capacidade do atendente em esclarecer dúvidas & & 2 & 3 & 4 & 5 & 6 & & 7 \\
\hline b) & Atualização das informações prestadas & & 2 & 3 & 4 & 5 & 6 & & 7 \\
\hline c) & Cumprimento do serviço a que se propõe & & 2 & 3 & 4 & 5 & 6 & & 7 \\
\hline d) & Atendimento das solicitações dentro de um prazo determinado & 1 & 2 & 3 & 4 & 5 & 6 & & 7 \\
\hline \multicolumn{2}{|c|}{ Presteza: } & \multicolumn{8}{|c|}{ Escala de opinião } \\
\hline a) & Horário de atendimento adequado às necessidades do usuário & & 2 & 3 & 4 & 5 & 6 & & 7 \\
\hline b) & Tempo para atendimento & & 2 & 3 & 4 & 5 & 6 & & 7 \\
\hline c) & Acesso aos serviços oferecidos pela SRH (inclusive via internet) & & 2 & 3 & 4 & 5 & 6 & & 7 \\
\hline d) & Divulgação de todas as informações e atualizações de interesse do servidor & & 2 & 3 & 4 & 5 & 6 & & 7 \\
\hline \multicolumn{2}{|r|}{ Segurança: } & \multicolumn{8}{|c|}{ Escala de opinião } \\
\hline a) & Clareza na transmissão das informações & & 2 & 3 & 4 & 5 & 6 & & 7 \\
\hline b) & Segurança transmitida pelo funcionário & 1 & 2 & 3 & 4 & 5 & 6 & & 7 \\
\hline c) & Organização dos funcionários no desempenho da função & & 2 & 3 & 4 & 5 & 6 & & 7 \\
\hline d) & Esforço do funcionário para prestar um bom atendimento & & 2 & 3 & 4 & 5 & 6 & & 7 \\
\hline \multicolumn{2}{|r|}{ Empatia } & \multicolumn{8}{|c|}{ Escala de opinião } \\
\hline a) & Entendimento do funcionário em relação à necessidade do usuário & & 2 & 3 & 4 & 5 & 6 & & 7 \\
\hline b) & Atendimento individualizado & 1 & 2 & 3 & 4 & 5 & 6 & & 7 \\
\hline c) & Interesse em atender às solicitações & & 2 & 3 & 4 & 5 & 6 & & 7 \\
\hline d) & Educação e gentileza dos funcionários & & 2 & 3 & 4 & & & & 7 \\
\hline
\end{tabular}




\section{PERFIL DO SERVIDOR}

Por gentileza, favor responder as questões abaixo:

1. Sexo:
( ) Masculino
( ) Feminino

\section{Faixa etária:}
( ) 18 a 29 anos
( ) 30 a 39 anos
( ) 40 a 49 anos
( ) 50 a 59 anos
( ) acima de 60 anos

\section{Escolaridade:}
( ) Fundamental incompleto
( ) Fundamental completo
( ) Médio incompleto
( ) Médio completo
( ) Superior incompleto
( ) Superior completo
( ) Especialista
( ) Mestre
( ) Doutor

\section{Vínculo à FUB:}

( ) Técnico administrativo - Quadro Permanente

( ) Prestador de Serviços

( ) Contrato através de empresa Terceirizada

( ) Docente

( ) Outros (favor citar):

\section{Centro de Custo:}

\section{Tempo de serviço na FUB:}
( ) de 0 a 05 anos
( ) de 06 a 10 anos
( ) de 11 a 15 anos
( ) de 16 a 20 anos
( ) de 21 a 25 anos
( ) acima de 26 anos 